University of South Florida

DIGITAL COMMONS

@ UNIVERSITY OF SOUTH FLORIDA
Digital Commons @ University of

South Florida

8-1-2016

\title{
Characterization of Transit Ride Quality
}

CUTR

Follow this and additional works at: https://digitalcommons.usf.edu/cutr_nctr

\section{Recommended Citation}

"Characterization of Transit Ride Quality," National Center for Transit Research (NCTR) Report No. CUTRNCTR-RR-2016-07, Center for Urban Transportation Research, University of South Florida, 2016.

DOI: https://doi.org/10.5038/CUTR-NCTR-RR-2016-07

Available at: https://scholarcommons.usf.edu/cutr_nctr/53

This Technical Report is brought to you for free and open access by the National Center for Transit Research (NCTR) Archive (2000-2020) at Digital Commons @ University of South Florida. It has been accepted for inclusion in Research Reports by an authorized administrator of Digital Commons @ University of South Florida. For more information, please contact digitalcommons@usf.edu. 


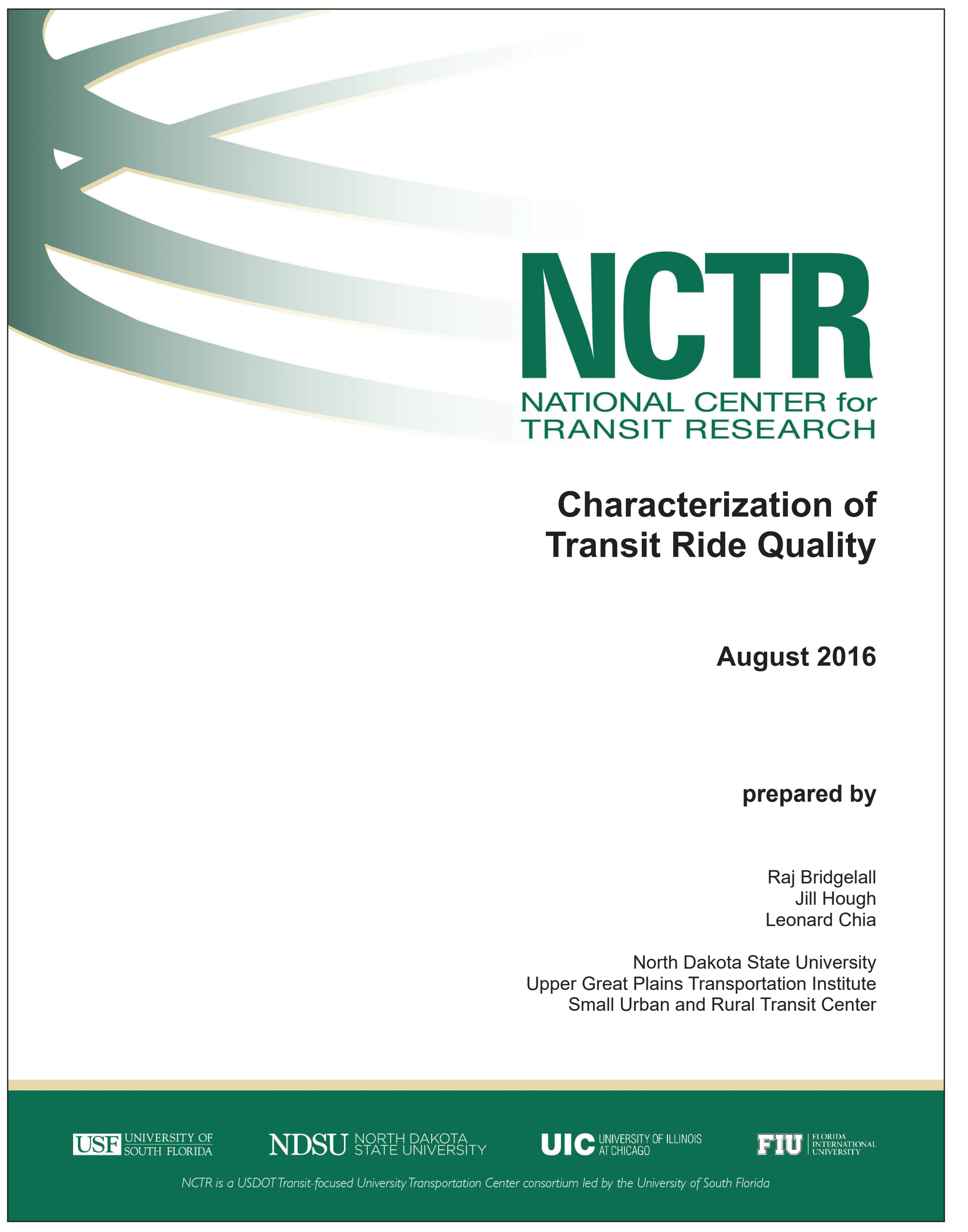




\section{Disclaimer}

The contents of this report reflect the views of the authors, who are responsible for the facts and the accuracy of the information presented herein. This document is disseminated under the sponsorship of the Department of Transportation University Transportation Centers Program and the Florida Department of Transportation, in the interest of information exchange. The U.S. Government and the Florida Department of Transportation assume no liability for the contents or use thereof.

The opinions, findings, and conclusions expressed in this publication are those of the authors and not necessarily those of the State of Florida Department of Transportation. 


\title{
Characterization of Transit Ride Quality
}

\author{
Prepared for: \\ U.S. Department of Transportation \\ Prepared by: \\ Dr. Raj Bridgelall (PI) \\ Dr. Jill Hough \\ Leonard Chia \\ Upper Great Plains Transportation Institute \\ North Dakota State University \\ Fargo, North Dakota
}

Final Report

21177060-NCTR-NDSU09

August 2016

\section{National Center for Transit Research}

A USDOT Transit-focused University Transportation Center consortium led by University of South Florida

4202 E. Fowler Avenue, CUT100, Tampa FL 33620-5375 www.nctr.usf.edu

Member universities: University of South Florida, North Dakota State University, University of Illinois at Chicago, Florida International University 


\section{Metric Conversion}

\begin{tabular}{|c|c|c|c|c|}
\hline SYMBOL & WHEN YOU KNOW & MULTIPLY BY & TO FIND & SYMBOL \\
\hline \multicolumn{5}{|c|}{ LENGTH } \\
\hline in & inches & 25.4 & millimeters & $\mathrm{mm}$ \\
\hline ft. & feet & 0.305 & meters & $\mathrm{m}$ \\
\hline yd. & yards & 0.914 & meters & $\mathrm{m}$ \\
\hline mi & miles & 1.61 & kilometers & $\mathrm{km}$ \\
\hline \multicolumn{5}{|c|}{ VOLUME } \\
\hline fl. oz. & fluid ounces & 29.57 & milliliters & $\mathrm{mL}$ \\
\hline gal & gallons & 3.785 & liters & $\mathrm{L}$ \\
\hline $\mathbf{f t}^{3}$ & cubic feet & 0.028 & cubic meters & $\mathrm{m}^{3}$ \\
\hline$y d^{3}$ & cubic yards & 0.765 & cubic meters & $\mathrm{m}^{3}$ \\
\hline \multicolumn{5}{|c|}{ NOTE: volumes greater than $1000 \mathrm{~L}$ shall be shown in $\mathrm{m}^{3}$} \\
\hline \multicolumn{5}{|c|}{ MASS } \\
\hline oz. & ounces & 28.35 & grams & $\mathrm{g}$ \\
\hline lb. & pounds & 0.454 & kilograms & $\mathrm{kg}$ \\
\hline $\mathbf{T}$ & Short tons (2000 lb.) & 0.907 & $\begin{array}{c}\text { megagrams } \\
\text { (or "metric ton") }\end{array}$ & Mg (or "t") \\
\hline \multicolumn{5}{|c|}{ TEMPERATURE (exact degrees) } \\
\hline${ }^{\circ} \mathbf{F}$ & Fahrenheit & $\begin{array}{c}5(F-32) / 9 \\
\text { or }(F-32) / 1.8\end{array}$ & Celsius & ${ }^{\circ} \mathrm{C}$ \\
\hline
\end{tabular}




\section{Technical Report Documentation}

\begin{tabular}{|c|c|c|c|}
\hline $\begin{array}{l}\text { 1. Report No. } \\
2117-9060-02-C\end{array}$ & \multicolumn{2}{|c|}{ 2. Government Accession No. } & 3. Recipient's Catalog No. \\
\hline \multicolumn{2}{|c|}{$\begin{array}{l}\text { 4. Title and Subtitle } \\
\text { Characterization of Transit Ride Quality }\end{array}$} & \multicolumn{2}{|l|}{$\begin{array}{l}\text { 5. Report Date } \\
\text { August } 2016\end{array}$} \\
\hline \multicolumn{4}{|c|}{ 6. Performing Organization Code } \\
\hline \multicolumn{2}{|c|}{$\begin{array}{l}\text { 7. Author(s) } \\
\text { Dr. Raj Bridgelall, Dr. Jill Hough, Leonard Chia } \\
\text { Upper Great Plains Transportation Institute } \\
\text { North Dakota State University } \\
\text { Fargo ND }\end{array}$} & \multicolumn{2}{|c|}{ 8. Performing Organization Report No. } \\
\hline \multicolumn{2}{|c|}{$\begin{array}{l}\text { 9. Performing Organization Name and Address } \\
\text { National Center for Transit Research } \\
\text { Center for Urban Transportation Research (CUTR) } \\
\text { University of South Florida } \\
4202 \text { East Fowler Avenue, CUT100 } \\
\text { Tampa, FL 33620-5375 }\end{array}$} & \multicolumn{2}{|c|}{ 10. Work Unit No. (TRAIS) } \\
\hline \multicolumn{4}{|c|}{ 11. Contract or Grant No. } \\
\hline \multicolumn{2}{|c|}{$\begin{array}{l}\text { 12. Sponsoring Agency Name and Address } \\
\text { Research and Innovative Technology Administration } \\
\text { U.S. Department of Transportation } \\
\text { Mail Code RDT-30, } 1200 \text { New Jersey Ave SE, Room E33 } \\
\text { Washington, DC 20590-0001 }\end{array}$} & \multicolumn{2}{|c|}{ 13. Type of Report and Period Covered } \\
\hline \multicolumn{4}{|c|}{ 14. Sponsoring Agency Code } \\
\hline \multicolumn{4}{|l|}{ 15. Supplementary Notes } \\
\hline \multicolumn{4}{|l|}{ 16. Abstract } \\
\hline \multicolumn{4}{|c|}{$\begin{array}{l}\text { Strategies often proposed to combat the growing traffic congestion problems of urban environments target } \\
\text { enhancements to increase the use of bus transit. Therefore, service providers are keen to identify and } \\
\text { understand factors that could attract more transit riders. Other than affordability, most researchers explored } \\
\text { convenience and stress factors such as schedule uncertainty, waiting time, travel time, crowding, noises, and } \\
\text { smells. However, few studies evaluated the significance of ride quality. The high cost to collect and analyze } \\
\text { roughness data likely deters such studies. This work developed a low-cost smartphone based method and } \\
\text { associated data transforms to characterize ride quality for non-uniform speed profiles. The method distinguished } \\
\text { between vibrations induced from road unevenness and operator behavior. The authors validated the accuracy of } \\
\text { the method by conducting surveys to characterize the perceived roughness intensities from buses traveling } \\
\text { routes of distinctly different roughness levels. The surveys found that smooth rides mattered to most } \\
\text { passengers, and that rough rides could even lead to some loss of ridership. Additionally, the authors proposed a } \\
\text { theory of roughness acclimation and provided some evidence that unlike objective measurements, subjective } \\
\text { assessments of ride quality could lead to significant biases and inconsistencies. }\end{array}$} \\
\hline \multicolumn{2}{|c|}{$\begin{array}{l}\text { 17. Key Words } \\
\text { Traffic congestion, urban environments, bus transit, } \\
\text { ridership, smartphone applications to transit }\end{array}$} & \multicolumn{2}{|c|}{$\begin{array}{l}\text { 18. Distribution Statement } \\
\text { No restrictions }\end{array}$} \\
\hline $\begin{array}{l}\text { 19. Security Classification } \\
\text { (of this report) } \\
\text { Unclassified }\end{array}$ & $\begin{array}{l}\text { 20. Security Classification } \\
\text { (of this page) } \\
\text { Unclassified }\end{array}$ & $\begin{array}{l}\text { 21. No. of Pages } \\
56\end{array}$ & 22. Price \\
\hline
\end{tabular}




\section{TABLE OF CONTENTS}

1. INTRODUCTION

2. LITERATURE REVIEW ...................................................................................................................4

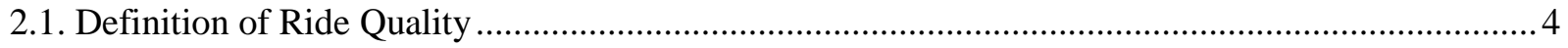

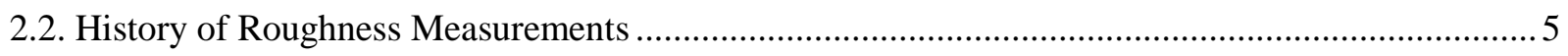

2.3. Subjective Methods of Roughness Characterizations............................................................... 6

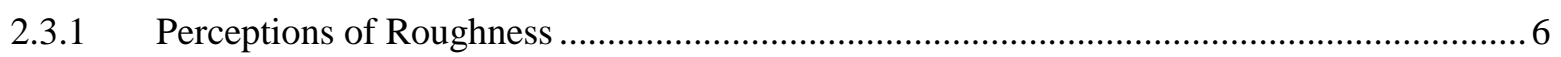

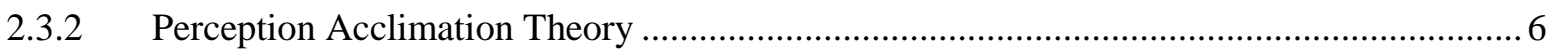

2.4. Objective Methods of Roughness Characterizations …................................................................. 7

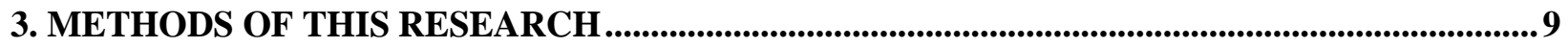

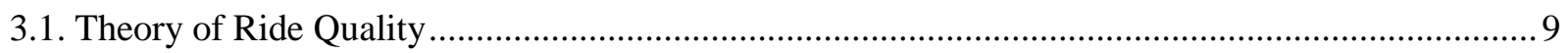

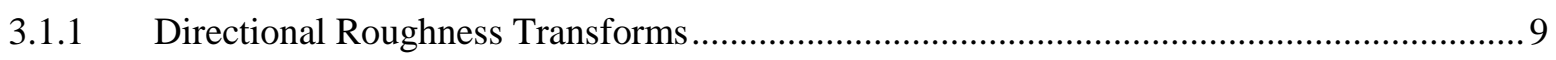

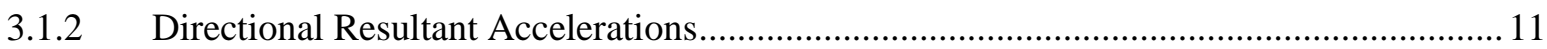

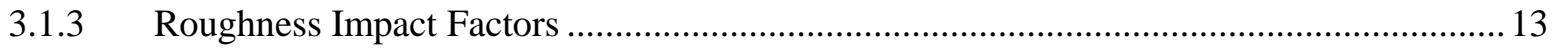

3.2. Data Collection and Processing Methods .................................................................................... 14

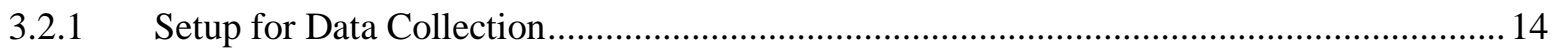

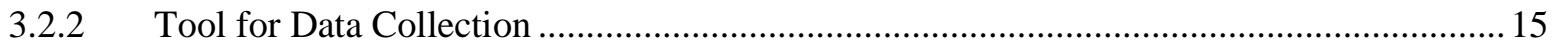

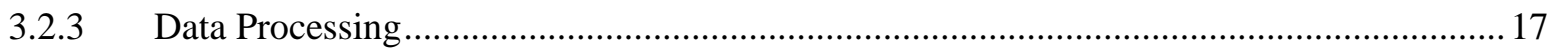

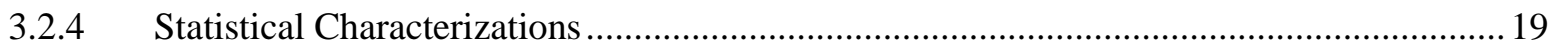

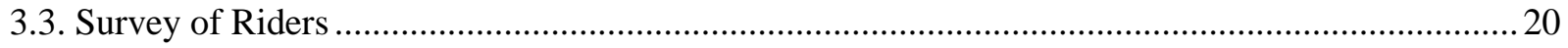

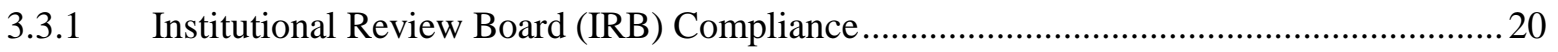

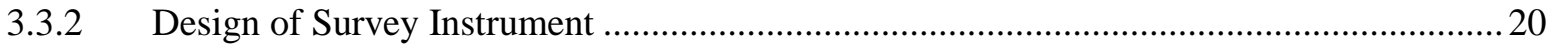

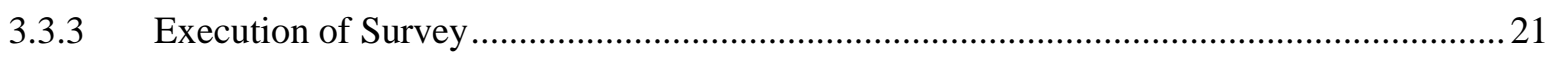

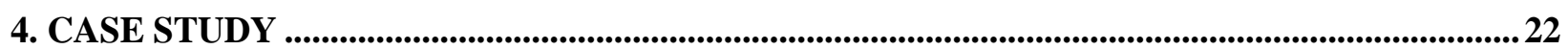

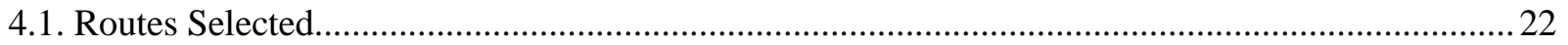

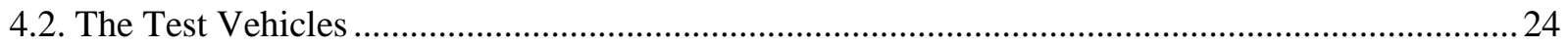

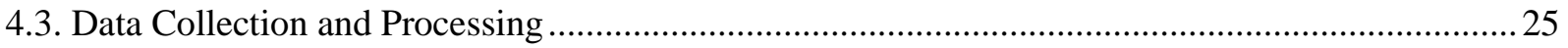

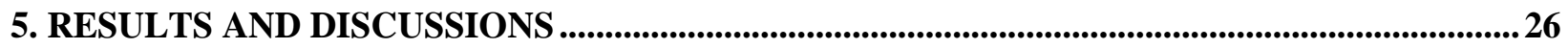

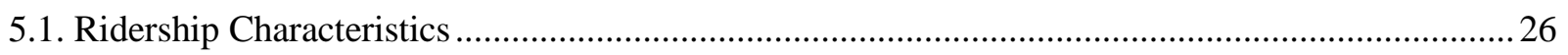

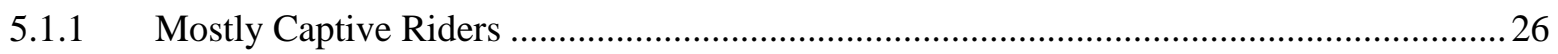

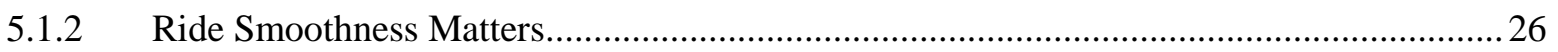

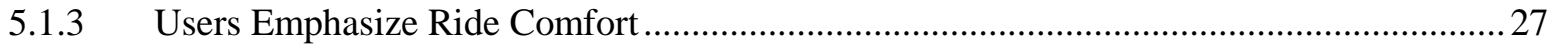

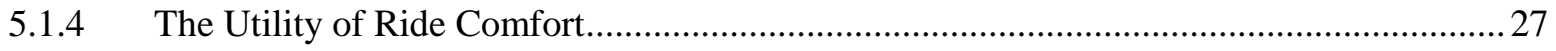

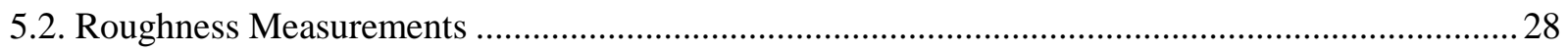

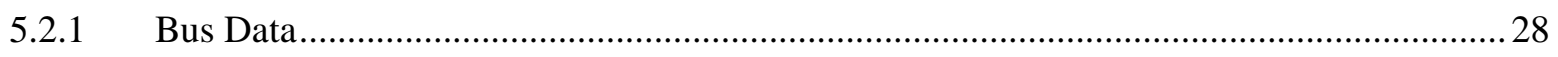

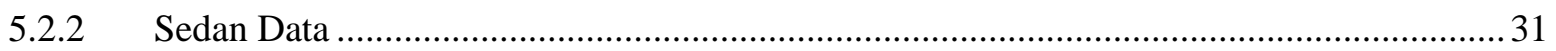




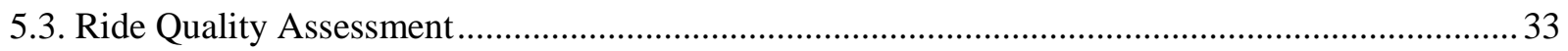

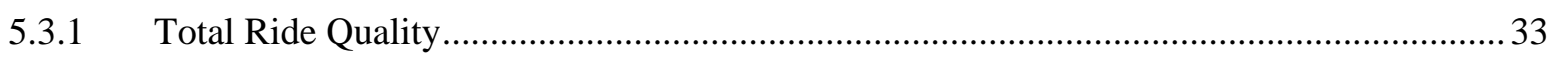

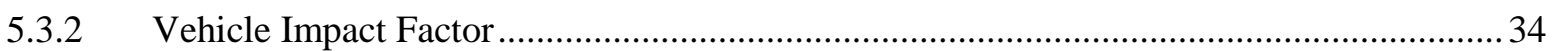

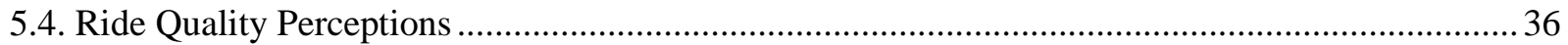

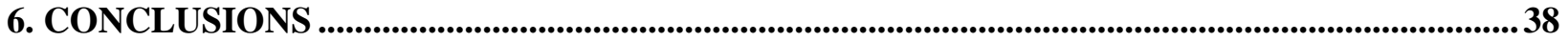

6.1. Ride Quality Measurements and Perceptions ............................................................................... 38

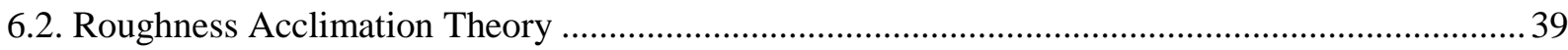

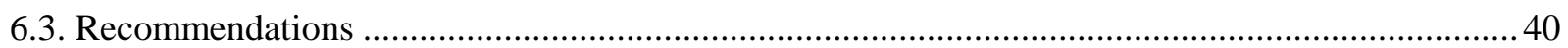

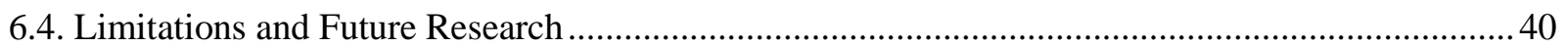

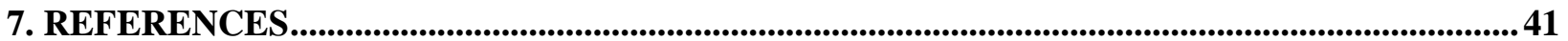




\section{LIST OF TABLES}

Table 3.1 Format of the Smartphone Application Data Log …...................................................... 16

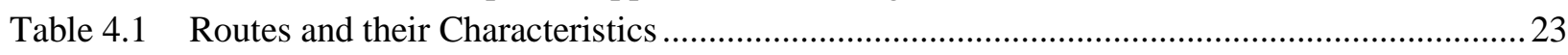

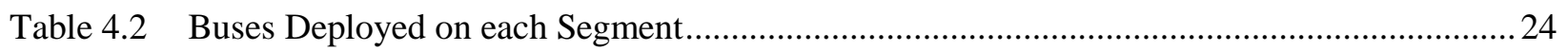

Table 5.1 Portion of the Bus Passengers with Access to Ride Alternatives...........................................26

Table 5.2 Importance Level for a Smooth Ride ............................................................................2 27

Table 5.3 Reason for Smoothness Being Very Important ..............................................................2

Table 5.4 Portion of the Bus Riders Who Would Consider Other Modes ..............................................28

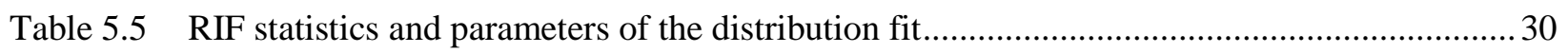

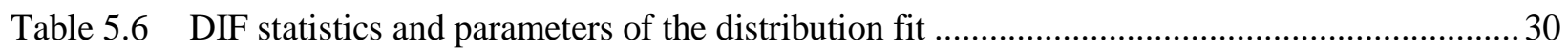

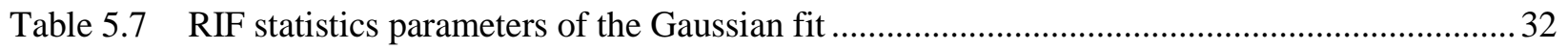

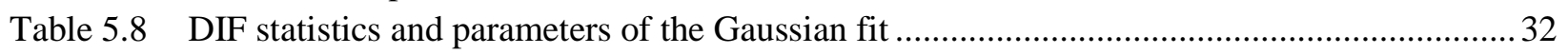

Table 5.9 Route Ride Quality from (a) All Buses (b) Pontiac Sedan (c) Dodge Sedan ......................... 33

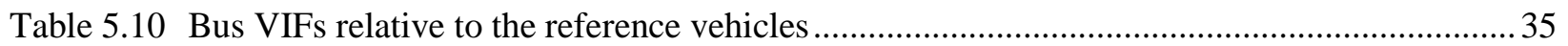

Table 5.11 Car/Bus statistics and fit of parameters with theoretical Gaussian distributions.....................35 


\section{LIST OF FIGURES}

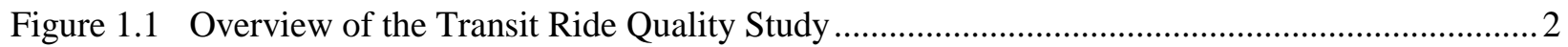

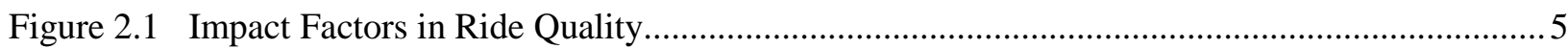

Figure 3.1 Transformation from Roughness Measurements to Total Ride Quality ................................ 10

Figure 3.2 Overview of Roughness Measurements and the Data Processing ...................................... 11

Figure 3.3 Reference Orientations for the Smartphone Data Collection Application ............................ 12

Figure 3.4 Top View of Data Collection Planform Installation on the Bus............................................ 14

Figure 3.5 Data Collection Platform a) Arrangement and b) Picture of Setup ...................................... 14

Figure 3.6 Screen Shot of the Smartphone Data Collection Application ............................................... 16

Figure 3.7 Calculation Procedure to Produce the Directional Roughness and Ride Quality Indices ....... 17

Figure 3.8 Data Sample from a Relatively Smooth Ride.............................................................. 17

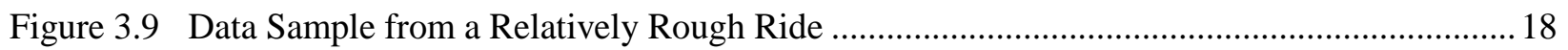

Figure 3.10 Front and Back Side of the Survey Card Used in the Study...............................................20

Figure 4.1 Overview of the Ride Segments Selected and the Bus Routes............................................23

Figure 4.2 Sample of the Buses used in the Case Study (Courtesy: Matbus.com) ..................................24

Figure 5.1 For each segment, the a) RIF and the b) DIF distributions from the bus traversals ...............29

Figure 5.2 For each segment, the a) RIF and the b) DIF distributions of sedan traversals......................31

Figure 5.3 Average of the RIFs for the buses and the reference sedan............................................... 33

Figure 5.4 For all segments, a) Car/Bus RIF ratios b) Car/Bus DIF ratios and c) VIF distributions ........34

Figure 5.5 For each Segment, Portions of Passengers Providing Ratings at Each Roughness Level....... 36

Figure 5.6 For each Route (a) Average TRQ measured at Each Rating b) Average TRQ Measured ....... 37 


\section{Acknowledgments}

The authors wish to thank Julie Bommelman (Transit Administrator of the City of Fargo), James Gilmour (Planning Director of the City of Fargo), and Gregg Schildberger (Senior Transit Planner for the City of Fargo) for their support in getting access to the buses for roughness measurements and to conduct surveys. Our gratitude also goes out to the following reviewers who helped to improve the clarity and value of this report: Kirk Burcar (Director of Production Engineering at New Flyer - a bus manufacturer), Dr. Nima Kargah-Ostadi, P.E. (Research Engineer at Fugro Roadware Inc. - a leading automated pavement ride quality evaluation company in the United States), Todd Belvo (Engineering Manager at BWI North America - a premier supplier of vehicle chassis, suspension, brakes, and other automotive parts to manufacturers), Eric Beaton (Senior Director of Transit Development for the New York City Department of Transportation), and Dr. Marcela Munizaga (Associate Professor at the University of Chile and President of the Chilean Society of Transportation Engineering). 


\section{ABSTRACT}

Strategies often proposed to combat the growing traffic congestion problems of urban environments target enhancements to increase the use of bus transit. Therefore, service providers are keen to identify and understand factors that could attract more transit riders. Other than affordability, most researchers explored convenience and stress factors such as schedule uncertainty, waiting time, travel time, crowding, noises, and smells. However, few studies evaluated the significance of ride quality. The high cost to collect and analyze roughness data likely deters such studies. This work developed a low-cost smartphone based method and associated data transforms to characterize ride quality for non-uniform speed profiles. The method distinguished between vibrations induced from road unevenness and operator behavior. The authors validated the accuracy of the method by conducting surveys to characterize the perceived roughness intensities from buses traveling routes of distinctly different roughness levels. The surveys found that smooth rides mattered to most passengers, and that rough rides could even lead to some loss of ridership. Additionally, the authors proposed a theory of roughness acclimation and provided some evidence that unlike objective measurements, subjective assessments of ride quality could lead to significant biases and inconsistencies. 


\section{EXECUTIVE SUMMARY}

The United Nations projected that by 2050 , most of the world's population will shift from rural to urban areas. Subsequently, urbanization will continue to challenge planners as the associated levels of traffic congestion increases. Planners often point to service enhancements of bus transit as an effective strategy to combat the growing traffic congestion problems of urban environments. As such, transit service providers wish to identify and understand the significance of factors that could attract more transit riders before investing resources to add capacity. Researchers often identify affordability, accessibility, convenience, and stress as factors that affect the choice of public transit. The latter two factors include parameters such as the uncertainty of schedules, waiting time, travel time, crowding, noises, and smells. However, few studies evaluated the significance of ride quality.

The high cost to collect and analyze roughness data is a likely deterrent to ride quality evaluations. In particular, deployments of existing high-speed instrumentation to measure roughness in urban environments, such as inertial profilers, are impractical because of the stop-and-go conditions. To address the affordability and scalability issue, this study developed a low-cost smartphone based method and associated data transforms to characterize ride quality, for any speed profile. The approach is transferrable to connected vehicles by using the same method to transform their inertial, velocity, and geospatial position data. The method distinguished between vibrations induced from road unevenness and operator behavior. The theories developed also quantified the vehicle impact factors. Those are the relative abilities of different vehicles to absorb inertial excitations. The authors validated the accuracy of the method by conducting surveys to characterize the perceived roughness intensities from buses traveling four routes of distinctly different roughness levels.

The surveys found that smooth rides mattered to most passengers. In fact, a noteworthy portion (21\%) of the passengers who perceived the ride to be rough would consider other modes of transportation. Hence, even though a majority of the riders were captive in this case study, many felt that rough rides could be a deterrent to choosing bus transit. Comfort was the top reason provided as a reason for the importance of a smooth ride. Additionally, the authors proposed a theory of roughness acclimation and provided initial evidence that unlike objective measurements, subjective assessments of ride quality could lead to significant biases and inconsistencies. Given the implications of this finding, the authors wish to conduct future research that will extend the experiment and sample sizes to additional roadways and urban settings. Statistics of the data collected using the objective means of ride quality characterizations developed in this research provided strong evidence that the mean of the measured values adequately estimated the ride quality experienced. In particular, the application of classical statistical tests for a normal distribution, and the relatively low margins-of-error obtained with sample sizes greater than 30 indicated that the estimates of ride quality will become increasingly consistent with greater data volume. This result points to connected vehicles as the ideal framework to integrate this approach because of the large and continuous data volumes anticipated.

The results of this research will provide agencies with a low-cost framework and tools to assess continuously the ride quality of transit services. Such assessments can inform decisions about operator training, equipment maintenance, and ridership enhancement programs. Smart city initiatives that urge urban planning practices to integrate diverse data sources and ideas from different agencies to realize synergies across the entire multimodal system will particularly benefit. For example, transit agencies can provide a connection from the ride quality database to highway asset management platforms. Such initiatives would allow highway agencies to leverage transit ride quality data for optimized urban roadway maintenance planning, and the prioritization of remediation needs. Subsequently, smoother roads will reduce vehicle operating costs, decrease roadway maintenance costs, and enhance the ride quality for all travelers. 


\section{INTRODUCTION}

Growing urban populations and the increasing levels of congestion in most cities worldwide encourages a search for solutions that would increase the use of public transit. Hence, urban planners and their stakeholders aim to identify the factors that could amplify a mode shift towards public transit. Conversely, factors that could deter the frequent use of public transit by contributing to negative perceptions of personal comfort and well-being are also of significant interest. In general, most studies of transit ride quality focused on convenience and stress factors such as schedule uncertainty, waiting time, travel time, crowding, noises, and smells (Dunlop, Casello and Doherty 2015). Very few studies evaluated ride roughness to quantify its significance as a potential deterrent to using public transit.

Transit ride quality is not a well-defined term in the literature. It could encompass a wide variety of factors such as the type and quality of onboard services, interior aesthetics and furniture design, road disturbances, operator behaviors, and characteristics of the vehicle dynamic responses. The Federal Highway Administration (FHWA) long recognized roughness as the most important measure of ride quality because it is the characteristic that is most evident to the traveling public (Perera, Byrum and Kohn 1998). This study added lateral and longitudinal accelerations to account for roughness induced by operator behaviors, and from anomalies that impact only one side of a vehicle. Therefore, this study aligns with the FHWA definition to focus on roughness as a dominant aspect of transit ride quality.

Very little is known about the impact of road roughness on transit ride quality or the level of importance that transit users place on experiencing a smooth ride. The lack of ride roughness data for local and urban roads may have been one reason for the scarcity of such studies. Existing methods of obtaining ride roughness data is expensive. They require expert practitioners and laborious data processing by trained personnel. Most agencies use specially instrumented vehicles called inertial profilers to measure the elevation profile of the road surface. Special vehicle models then convert that data into a standard measure of ride quality called the international roughness index (IRI). Inertial profilers must travel at a relatively constant speed to collect good data quality to use the model effectively. Hence, agencies tend to avoid ride quality characterizations of local and urban roads because stop-and-go conditions tend to ruin the elevation profile measurements (Karamihas 2016).

Another factor that may have limited transit ride quality studies in the past was the conventional thinking that bus transit agencies do not influence decisions in other agencies to prioritize the repair of rough roads. However, the proliferation of smart city initiatives worldwide is changing that mindset. Smart city initiatives encourage integrated multimodal transportation planning that involves agencies across various domains of the planning process (USDOT 2015). Smart city developments benefit from integrated and collaborative decision-making among different transportation agencies to identify synergies, reduce costs, and promote safety across the multimodal and intermodal system. Hence, governments at all levels have been encouraging and funding innovative approaches to develop transportation solutions that integrate multiple modes of travel to address the mobility needs of growing urban populations. Subsequently, transit agency inputs are becoming more critical to the urban planning processes, especially when they involve transit oriented developments (Dittmar and Ohland 2012).

One of the first studies on transit ride experiences found that the subjective rating of ride comfort was highly correlated to the frequency and level of vibrations experienced (Park 1976). A later study established that there is a strong linkage between transit ridership and the perception of service quality in terms of comfort (Benjamin and Price 2006). However, roughness was not specifically evaluated as a comfort factor. With respect to ridership retention or enhancements, at least one study established that poor ride quality was a major issue of customer concern (Peterson and Molloy 2007). In addition to the potential impact on transit ridership, rough roads affect vehicle operating costs (Abaynayaka, et al. 1976). 
That is, road roughness can increase bus repair and maintenance costs by more than $30 \%$ (Dreyer and Steyn 2015), and increase vehicle fuel consumption by as much as 5 percent (Klaubert 2001).

The main purpose of this research was to quantify the level of importance of a smooth ride and to determine the degree to which rough rides could deter the frequent use of public bus transit. The approach utilized was to develop an objective means of measuring the bus ride quality, and to compare those measurements to subjective perceptions of roughness. Therefore, the objectives of this research were to:

1. Develop a new method of objectively measuring the total ride quality (TRQ) of transit services as they operate normally at non-uniform speeds

2. Identify and measure the TRQ of four bus transit segments with distinct differences in roughness levels

3. Survey the perceived level of ride quality on select segments of the bus routes

4. Assess the level of importance of a smooth bus ride

5. Develop a theory that explains the relationships observed between the perceived levels of roughness and the objective measurements

Figure 1.1 provides an overview of the study approach. A smartphone aboard the buses collected inertial, velocity, and geospatial position data. A post-processing algorithm converted the data into the roughness components needed to compute the total ride quality (TRQ). The roughness components are road impact factors (RIFs), driver impact factors (DIFs), and vehicle impact factors (VIFs). Quantification of the VIF requires data collection from a reference vehicle, such as a passenger sedan.

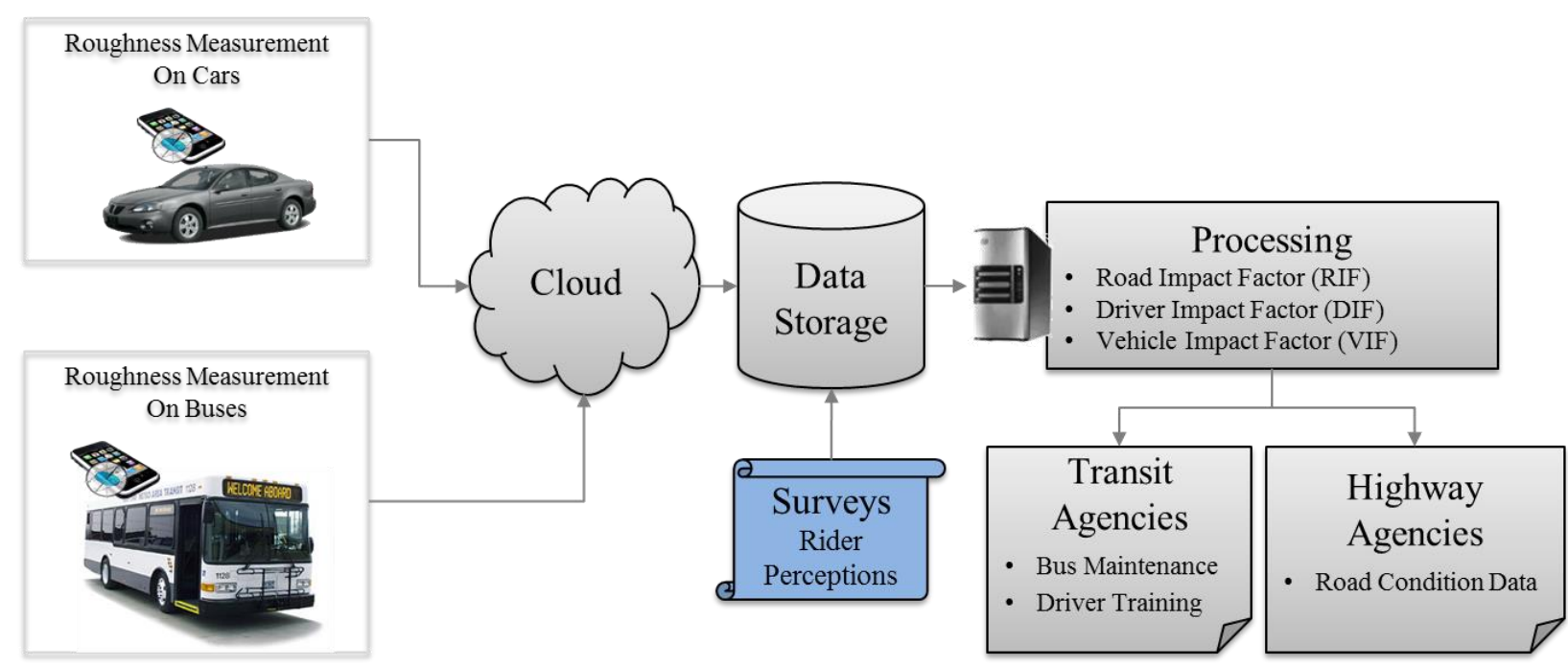

Figure 1.1 Overview of the Transit Ride Quality Study

The approach is transferrable to connected vehicles by using the same method to analyze their inertial, velocity, and geospatial position data. Practitioners can use this framework to visualize the data by overlaying color-coded TRQ values onto maps of the routes by using any suitable geographic information system (GIS) platform. Hence, transit agencies can use such a tool to help optimize bus maintenance timing and driver training programs. As part of the smart cities mindset, transit agencies can provide links 
to the data sources so that roadway agencies can use the ride quality data to forecast maintenance needs and to prioritize road repairs.

The remainder of this report is organized into 5 additional sections. Section 2 summarizes the literature review that focused on methods of ride quality characterizations. Section 3 establishes the theory of ride quality characterizations, describes the data collection and processing methods, and explains the design and execution of the ride quality perception surveys. Section 4 presents the case study that describes the test segments, the test vehicles, and the procedure for data collection and data preparation. Section 5 presents the results, establishing that smoothness matters to the bus users, and that some users would consider alternative modes of transportation when the ride is too rough. Subsection 5.2 presents statistics of the roughness measurements for the buses and the reference sedans that establishes high confidence in the convergence of the mean. Subsection 5.3 quantifies the total ride quality and vehicle impact factors based on the mean values measured in the previous section. Subsection 5.4 compares the perceptions of roughness levels to the objectively measured quantities and validates a theory that riders adapt to the roughness experienced. Finally, Section 6 provides the conclusions and outlines the future work. 


\section{LITERATURE REVIEW}

This section provides a definition and a historical overview of ride quality characterizations. The section describes both subjective and objective methods of roughness characterizations that are currently in use. Subjective methods utilize panels of observers to rate ride quality. Conversely, objective methods use instrumented vehicles to measure roughness levels. Subjective methods engage the human perception of roughness and, therefore lacks consistency. On the other hand, objective methods are more consistent but few studies have linked the roughness scale to levels of transit ride comfort or discomfort. This section exposes both the advantages and limitations of the prevailing methods, and introduces a theory of perception acclimation based on the tendency of humans to adapt.

\subsection{Definition of Ride Quality}

Practitioners use the term ride quality to indicate the degree to which a vehicle protects its occupants from factors that decrease ride comfort. Hence, factors that affect ride quality are numerous. They are summarized in Figure 2.1. The road impact factors (RIFs) are road surface unevenness and anomalies such as potholes, cracks, joints, and utility covers. The driver impact factors (DIFs) are operator behaviors such as abrupt braking, rapid acceleration, weaving, and speeding around curves. As shown in Figure 1.1, the RIFs and the DIFs can produce motions and noises that cause rider discomfort. The vehicle impact factors (VIFs) affect how riders perceive those disturbances. VIF depends mainly on vehicle suspension and handling characteristics. However, it is possible to include factors such as furniture design, interior aesthetics, and other features that are not within the scope of this study. Together, the RIF, DIF, and VIF result in the total ride quality (TRQ) experienced.

Roughness induced from uneven road surfaces adversely affects ride quality (Deusen 1967) (Brickman, et al. 1972). The ASTM E867 standard defines road roughness as "the deviation of a surface from a true planar surface with characteristic dimensions that affect vehicle dynamics and ride quality" (ASTM 1997). Manufacturers design vehicle suspension systems to attenuate vibrations at frequencies that could cause human discomfort or affect handling safety. Humans are most sensitive to vibrations between 4 and 8 Hertz (Griffin 1990). Hence, nearly all suspension systems attenuate vibrations in that frequency range (Jazar 2008). This leads to a similarity in the dynamic responses of vehicles. Hence, variations in road roughness, driver behaviors, vehicle handling, and suspension design could result in peak vibration levels that induce significant levels of discomfort for some riders.

Highway agencies regularly assess the performance of highway pavements by characterizing their ride quality. Regular assessments guide resource allocation strategies and maintenance scheduling.

To characterize ride quality, agencies consider only the RIF (R. Bridgelall 2014). The RIF is primarily a function of the vertical accelerations produced from the vehicle body bounces. The VIF varies with vehicle classification and primary function. Therefore, highway agencies use a fixed quarter-car called the Golden Car to standardize the VIF used to produce the IRI. Subsequently, the IRI ignores acceleration components from DIF and the actual vehicle handling characteristics. Hence, the IRI cannot adequately represent the TRQ. Section 3 of this report develops a theoretical foundation of the TRQ that considers all aspects of roughness generation and suppression at non-uniform speeds. 


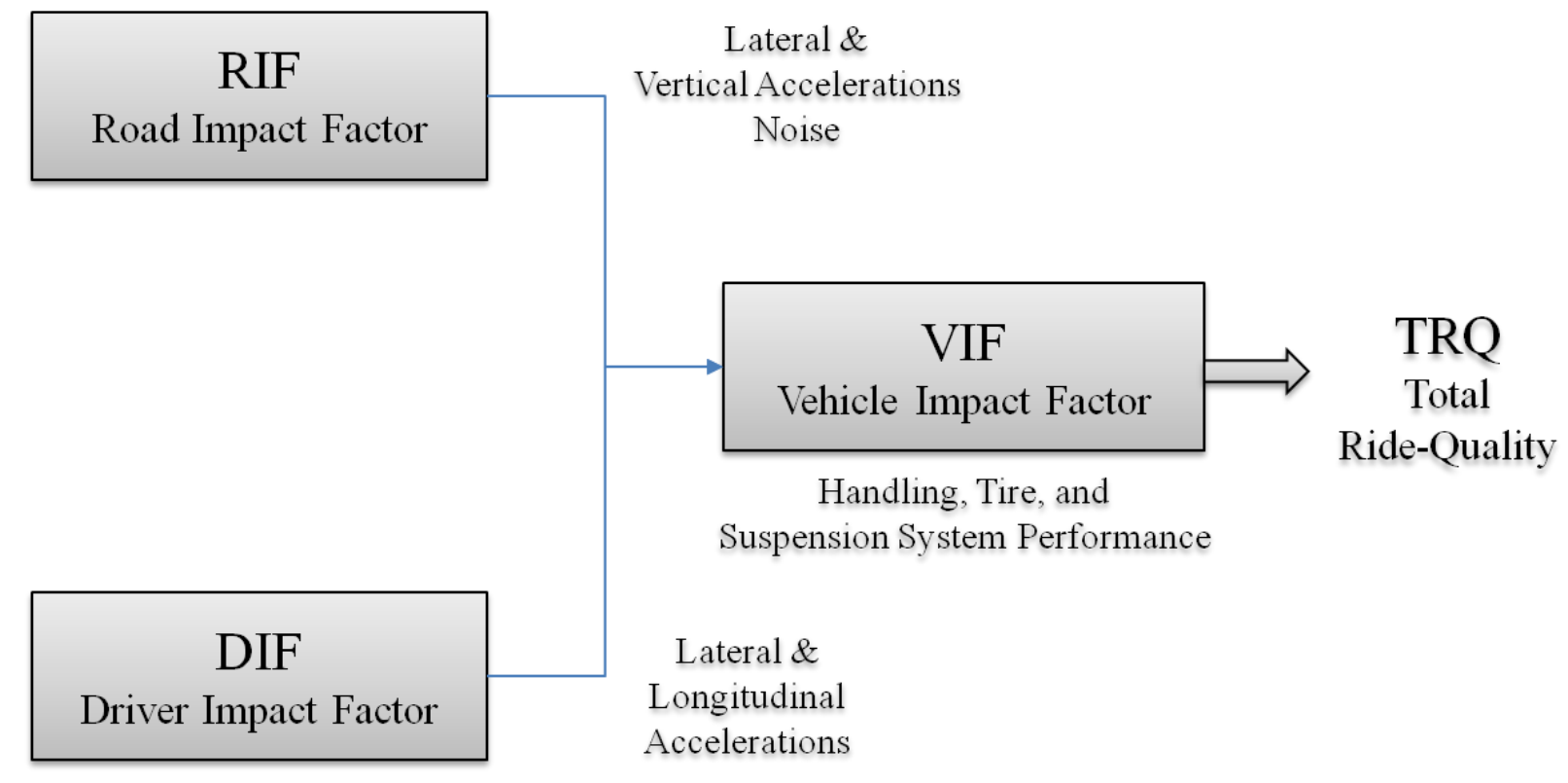

Figure 2.1 Impact Factors in Ride Quality

\subsection{History of Roughness Measurements}

From the earliest times of the first paved roads, society pursued the development of devices to produce objective, consistent, and repeatable measures of road roughness. Most of the early developments emphasized the RIF while ignoring the DIF and VIF. Surface roughness measurement tools have evolved from simple hand-held devices such as straightedge levels to sophisticated onboard computers and lasers that can measure elevation profiles at highway speeds. Prior to the $1900 \mathrm{~s}$, the sliding straightedge, called a Viagraph, was one of the first devices invented to measure surface roughness. It recorded the vertical deviations of a center piston (Hveem 1960). The Viagraph was the only instrument available until 1922 when the State of Illinois invented the Profilometer. It was essentially a straightedge on wheels. All straightedge type devices measure the depths below peaks of the roadway that touch the base of the device as it slides along the surface. Hence, measurements with such devices are slow and tedious.

With the introduction of faster moving vehicles, agencies soon became aware that motorists were more concerned with ride roughness than actual profile roughness. Around 1926, the State of New York developed the Via-Log to measure roughness. A stylus mounted to the front-axle recorded its movements relative to the body of the vehicle by marking its relative position on a turning roll of paper. Manufacturers later implemented the same concept in different ways through a combination of mechanical and electronic methods. Thereafter, practitioners named the category response-type road roughness measuring systems (RTRRMS). For repeatable measurements, manufacturers produced trailers with standardized mass-spring suspensions such as the Bureau of Public Roads (BPR) Roughometer introduced in 1941, and the Mays Ride Meter introduced in the 1960s. Soon thereafter, agencies discovered that the mechanical filtering action of a vehicle's suspension masked some of the RTRRMS roughness indicators that straightedge devices would normally report. This discrepancy led to additional investigations for improved methods.

During the early 1960s, the General Motors Research Laboratory (GMRL) produced the first contactless, high-speed device that incorporated basic principles of the straightedge (Spangler and Kelley 1966). Contactless depth measuring sensors replaced the center piston and the center wheels of straightedge 
devices. Acoustic sensors initially provided the depth measurement but manufacturers eventually replaced those with lasers in the 1990s. The GMRL device became a template for engineers to improve accuracy and reduce cost. An important shortcoming, however, was that the tire and suspension system differences of vehicles required some method of regular calibration. This challenge spurred considerable research to find the best means of calibrating devices to measure ride roughness (T. D. Gillespie 1992).

In 1982, the World Bank sponsored a series of experiments in Brazil to establish standard processes for calibrating and reporting roughness measurements. This event led to the definition of the IRI. The standardizing body selected a fixed speed of $80 \mathrm{~km} / \mathrm{h}$ (about $50 \mathrm{mph}$ ) to simulate the responses of a fixed quarter-car to the digitized elevation profile (Gillespie, Sayers and Queiroz 1986). Subsequently, characterizing ride quality in non-uniform speed environment such as local and urban roads becomes impractical (Karamihas 2016). Researchers and organizations has since proposed many other statistics to characterize ride roughness. However, the IRI remained the most widely used (ASTM 2015).

\subsection{Subjective Methods of Roughness Characterizations}

The American Association of State Highway and Transportation Officials (AASHTO) conducted road testing from 1956 to 1961 in Ottawa, Illinois to define a present serviceability index (PSI). It became the first single-number summary of pavement roughness (Carey and Irick 1960). The researchers defined the PSI as a regression relation between the output of a roughness-measuring device and the average ratings of ride quality from a panel of observers. Purdue University researchers found that at fixed speeds, the method provided excellent correlation with panel ratings for rigid pavements but not for flexible pavements (Nakamura and Michael 1963). The Kentucky Department of Highways (KDOH) repeated the Purdue University experiments at different speeds. They found that the method was nonlinear with speed and that the indices for flexible and rigid pavements were uncorrelated (Rizenbergs 1965).

\subsubsection{Perceptions of Roughness}

Researchers have long conducted studies to determine correlations between perceptions of roughness and the objective measures of roughness from various devices. For example, researchers found that the rootmean-square vertical acceleration (RMSVA) obtained from a Mays Ride Meter, which is the difference between adjacent slope measurements, was useful in equipment calibration, but unreliable as a predictor of panel ratings (Hudson, et al. 1983). Generally, the lack of agreement between various roughness measuring devices circumvented the definition of a uniformly accepted single-index characterization of roughness until the World Bank defined the IRI in 1982 as a standard, objective measure of roughness (Gillespie, Sayers and Queiroz 1986).

The international standard on human exposure to mechanical vibration and shock (ISO 2631) characterizes the effects of roughness on Whole-body vibration (WBV) to create awareness of vibration health risks (ISO 2631-1 1997). The standard suggests vertical acceleration limits that others (Cantisani and Loprencipe 2010) have translated into road roughness limits in terms of the IRI. However, the simplified quarter-car model of the IRI excludes roughness from lateral and longitudinal directions. A model that has many more degrees of freedom can simulate roughness is all directions that the user experiences (Zhang, Zhao and Yang 2014), but they are also more complex to apply and utilize. In general, there is a gap in methods to characterize roughness in all directions as a vehicle travels at nonuniform speeds (Múčka 2015).

\subsubsection{Perception Acclimation Theory}

Differences in human physiology result in a range of sensations that cause different perceptions of comfort levels. A comprehensive literature search did not locate a study that compares perceived ride 
roughness with the actual level of roughness experienced. However, adjacent fields that study thermal comfort found that the perception of neutrality acclimates to the environment (Spagnolo and Dear 2003). In particular, the perceived thermal neutrality of outdoor settings was significantly higher than that of indoor settings. Thermal adaptation in humans result in a gap between the actual and the perceived temperature levels (Sharmin and Steemers 2015). Therefore, the authors of this study posit that roughness neutrality will exhibit a similar gap between the levels perceived and those measured with objective means. That is, the roughness neutrality level will expectedly acclimate to the average roughness of the ride. As a perception acclimation theory does not yet exist for roughness, the authors will call this the roughness acclimation theory.

\subsection{Objective Methods of Roughness Characterizations}

The IRI is the most widely accepted method to characterize ride quality objectively from road impact factors. It is the accumulation of the absolute rate differences between the sprung- and unsprung-mass of a reference quarter-car moving at a fixed speed of $80 \mathrm{~km} / \mathrm{h}$ (T. D. Gillespie 1981). Producing the IRI requires special instrumentation to measure the elevation profile of a wheel path, and simulation software to transform that data into the index (Janoff 1990). Nearly all highway agencies use inertial profilers to collect road profile data (The Transtec Group 2012). A reference procedure later transforms the digitized road profile samples into the IRI or the PSD. Inertial profilers integrate a laser and position sensitive light sensor to measure the elevation profile while traveling at highway speeds. Although standards have since been in place to specify their functionality and performance (AASHTO 2010), inertial profilers differ in the quality of the data that they report (Ksaibati, et al. 1999), (Dyer, Boyd and Dyer 2005). The method of sampling the road profile is a primary reason for the differences in data quality. Laser-based height sensors record the distance from the base of the vehicle to the pavement surface. Accelerometers above the height sensors record the vertical acceleration of the sensor to correct for reference plane bounces. In theory, double integration of the vertical acceleration signal would recover the vertical displacement of the vehicle. Practically, however, noise and initial conditions tend to create additional issues that limit their use in urban and local roads where the profiling vehicle must travel at low speeds and accommodate stop-and-go conditions (Karamihas 2016).

Although reports (NCHRP Report 334) indicate that most agencies now use inertial profilers (Hyman, et al. 1990), the literature has very little information about their cost to acquire, operate, and maintain. One study reported the contracted pavement profile data collection and analysis costs ranged from $\$ 2.23 / \mathrm{mile}$ to $\$ 10.00 /$ mile, with an average of $\$ 6.12 /$ mile (McGhee 2004). However, the reported costs did not include overhead such contract administration, equipment maintenance, and equipment depreciation. In general, the relatively high expense and labor requirements of existing approaches prevent agencies from monitoring large portions of their roadway network more often than once annually.

The application of elevation profile measurements to a fixed and simplified vehicle model, and the assumption of a fixed speed results in some significant limitations of the IRI. As such, researchers cautioned against using the IRI by demonstrating that profiles with distinctly different roughness features can produce the same IRI (Kropáč and Múčka 2005). Agencies worldwide found that the IRI masks wavelengths that produced roughness for both local roads and highways (Brown, Liu and Henning 2010). Given those limitations, researchers revisited the accelerometer-based method in the late 1980s to provide a more sensitive indicator of truck operating costs and cargo damage than the IRI (Todd and Kulakowski 1989). Studies found that the suspension system vertical acceleration was the largest contributor to the dynamic axle loads that heavy trucks generate (Papagiannakis 1997). Consequently, researchers proposed a new index based on the Power Spectral Density (PSD) of the body vertical acceleration of a reference truck model. The reference speed and segment length was $80 \mathrm{~km} / \mathrm{h}$ and $0.5 \mathrm{~km}$, respectively. The truck roughness index is the square root of the area under the PSD from zero to 50 Hertz. The researchers found that the new index is uncorrelated with the IRI. 
The limitations of the IRI extend to this study. The first limitation is that the simulation of a fixed quartercar does not reflect the vibration modes induced in the actual vehicle. The second limitation is that the fixed simulation speed of $80 \mathrm{~km} / \mathrm{h}$ does not reflect the effects of road roughness at other speeds. The third limitation is that the IRI does not reflect roughness from driver impact factors. Furthermore, most transit agencies do not have the budget and expertise required to obtain and operate the special instrumentation needed to measure the elevation profile of the selected bus routes.

Additional approaches have evolved based on mobile computing (Hyman, et al. 1990) and other automated data collection techniques that involve more complex sensors (McGhee 2004). In more recent developments, researchers have been investigating alternative methods of roughness data collection that use accelerometers and speed sensors aboard connected vehicles (R. Bridgelall 2014). The seemingly unbounded increase in performance levels and cost reduction of smartphones has continually enticed researchers to revisit techniques that involve transformations of the accelerometer data to produce single indices of roughness. However, the findings continue to demonstrate that unless calibrated with the responses of individual vehicles at fixed speeds, correlation with the IRI remains poor. Transformations of the smartphone accelerometer signal include the root-mean-square (RMS) (Dawkins, et al. 2011), the full-car vibration power (Katicha, Khoury and Flintsch 2015), the Fourier Transform magnitude (Douangphachanh and Oneyama 2013), the magnitude weighted Short-Time Fourier Transform (Yagi 2013), and linear regression of the power spectral density ( $\mathrm{Du}$, et al. 2014). As the need to calibrate transformations of the accelerometer data from individual vehicles does not provide any substantial improvement over the RTRRMS methods, the IRI has prevailed as the most common representation of road roughness. In fact, many proposals for new indices involve a modification of the IRI procedure (Múčka 2015). 


\section{METHODS OF THIS RESEARCH}

The high cost of deploying specially instrumented vehicles to produce the IRI limits ride quality characterizations to relatively small portions of the highway network. Hence, roughness data is generally not available for the local and urban roads that bus transit uses. Furthermore, transit agencies do not generally measure ride quality. In previous research, the authors developed a connected vehicle method to provide continuous RIF measurements for all roadways, including local and unpaved roads (R. Bridgelall 2014). This research will extend that method to produce the TRQ by integrating the RIFs, DIFs, and VIFs. This section first defines new directional roughness indices that make up the RIFs and DIFs. Subsections describe the setup for data collection, the smartphone app used to collect the inertial and geospatial position data, the data processing, statistical characterizations of the measurements, and the survey preparation.

\subsection{Theory of Ride Quality}

This section develops the model to quantify ride quality in terms of all the relevant roughness impact factors. The TRQ is defined as the resultant vector magnitude of the Road Impact Factor and Driver Impact Factor. The impact factors are in turn derived by integrating accelerations in the three orthogonal directions of three-dimensional space. The Vehicle Impact Factor (VIF) is defined relative to the vibration suppression ability of a reference four door sedan. Figure 3.1 illustrates the mathematical transformation of the signal samples from the accelerometer, gyroscope, velocity sensor, and timer to directional referenced roughness indices that in turn produce the impact factors that lead to a final quantification of the ride quality experienced. The next sections define the signal transformations that produce the directional roughness indices from the resultant accelerations in three dimensions, and the roughness impact factors.

\subsubsection{Directional Roughness Transforms}

The author previously developed a directional roughness transform that summarizes ride roughness in the vertical, lateral, or longitudinal directions relative to a traversal trajectory (R. Bridgelall 2014). The Vertical Roughness Index (VRI) is a summary of the roughness energy density in the resultant vertical (zaxis) direction such that

$$
R_{z}^{L}=\sqrt{\frac{1}{L} \sum_{n=0}^{N-1}\left|g_{\mathrm{z}[n]} v_{n}\right|^{2} \delta t}
$$

Equation (1) expresses the VRI, denoted $R_{z}^{L}$ as the average g-force magnitude experienced per unit of longitudinal distance $L$ traveled. Accelerometers and speed sensors produce samples $n$ of the measured vertical acceleration $g_{\mathrm{z}[n]}$ and the instantaneous traversal speed $v_{n}$, respectively. For an average sample period of $\delta t$, the average spatial resolution achievable is $\delta L=v_{n} \delta t$. Bridgelall (2014) demonstrated that the VRI is directly proportional to the IRI for any fixed traversal speed. 


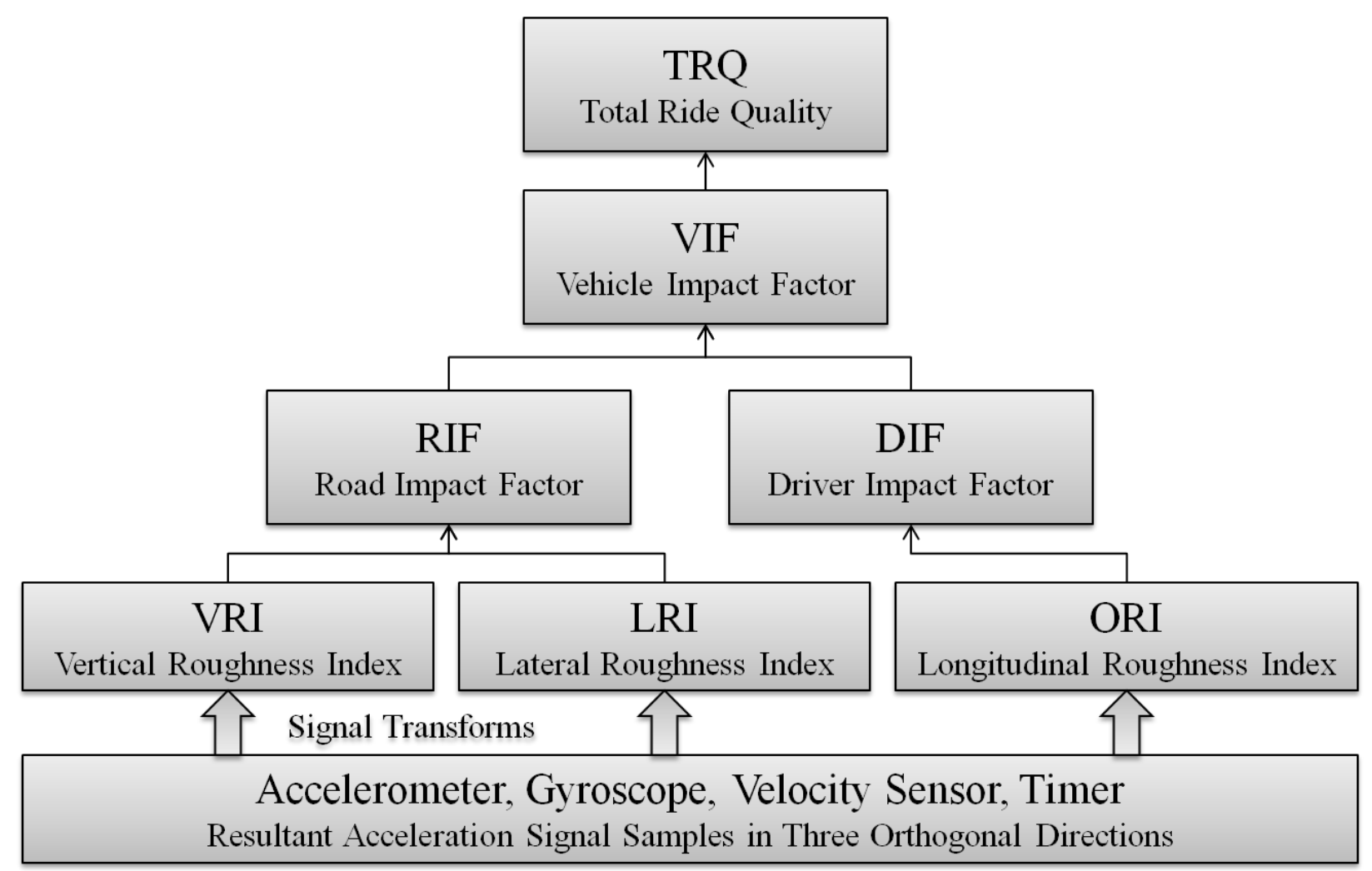

Figure 3.1 Transformation from Roughness Measurements to Total Ride Quality

Directional roughness indices are similarly defined for accelerations in the resultant lateral (x-axis) and the resultant longitudinal (y-axis) directions, respectively. The Lateral Roughness Index (LRI) $R_{x}^{L}$ is defined as

$$
R_{x}^{L}=\sqrt{\frac{1}{L} \sum_{n=0}^{N-1}\left|g_{\mathrm{x}[n]} v_{n}\right|^{2} \delta t}
$$

and the Longitudinal Roughness Index (ORI) $R_{y}^{L}$ is defined as

$$
R_{y}^{L}=\sqrt{\frac{1}{L} \sum_{n=0}^{N-1}\left|g_{\mathrm{y}[n]} v_{n}\right|^{2} \delta t} .
$$

It is important to note that the VRI is directly proportional to the IRI only for a fixed speed. However, unlike the IRI, the VRI reports directly the actual roughness experienced at any speed because it integrates the instantaneous velocity changes. Therefore, the VRI is applicable to traffic situations where the speed profile changes continuously. The VRI is also distinguishable from the RMS. Although similar in formulation, the RMS is a time average of vibration responses. Therefore, unlike the VRI, the RMS will produce non-zero values even when the vehicle is parked. The VRI produces a zero for vehicles that are not in motion. 
The choice of resolution lengths $L$ is a function of the application. For example, some applications may seek only a summary of the ride quality for 1000-meter segments of a road. In such a situation, the analyst would set $L=1000$. Other applications may seek to localize anomalies within a resolution of a few meters. In such situations, the analyst may select $L=1$, for example, to distinguish among closely positioned potholes or to locate a specific pavement joint (Bridgelall, et al. 2016). The minimum possible resolution length setting is $\delta L$ and the maximum is the length of the entire road segment for which data is collected. A hybrid approach is also possible that both localizes anomalies and provides a roughness measure for entire segment lengths. That would be the mean of an index for smaller $L$-length segments. For instance, the batch mean of the LRI is denoted $\bar{R}_{x}^{L}$ and defined as

$$
\bar{R}_{x}^{L}=\frac{1}{K} \sum_{k=0}^{K-1} R_{x}^{L}[k]
$$

where $K$ is the number of $L$-length segments across the entire segment. For this application, the authors use a resolution length of $L=10$ meters. This choice facilitates an integer increment for visualizing and plotting roughness. It also represents an integration of roughness energy during the time that a typical 30to 40 -feet bus (circa 9 to 12 meters) crosses a particular roadway anomaly.

\subsubsection{Directional Resultant Accelerations}

When secured to a flat surface, their embedded accelerometers of a typical smartphone can measure linear vibration intensities in three directions. Their embedded gyroscopes can measure the orientation changes of the surface in three angular directions. Smartphones also contain global positioning system (GPS) receivers, timers, and velocity sensors that can produce the data needed to calculate the three directional roughness indices (VRI, LRI, ORI) defined in Equations (1) to (3). Previous research by the authors determined the minimum sample rate settings for each sensor type to be 64 Hertz (R. Bridgelall 2014). Achieving a higher sample rate increases the fidelity of the signal relative to noise.

Figure 3.2 provides an overview of the measurement and the data processing procedures.

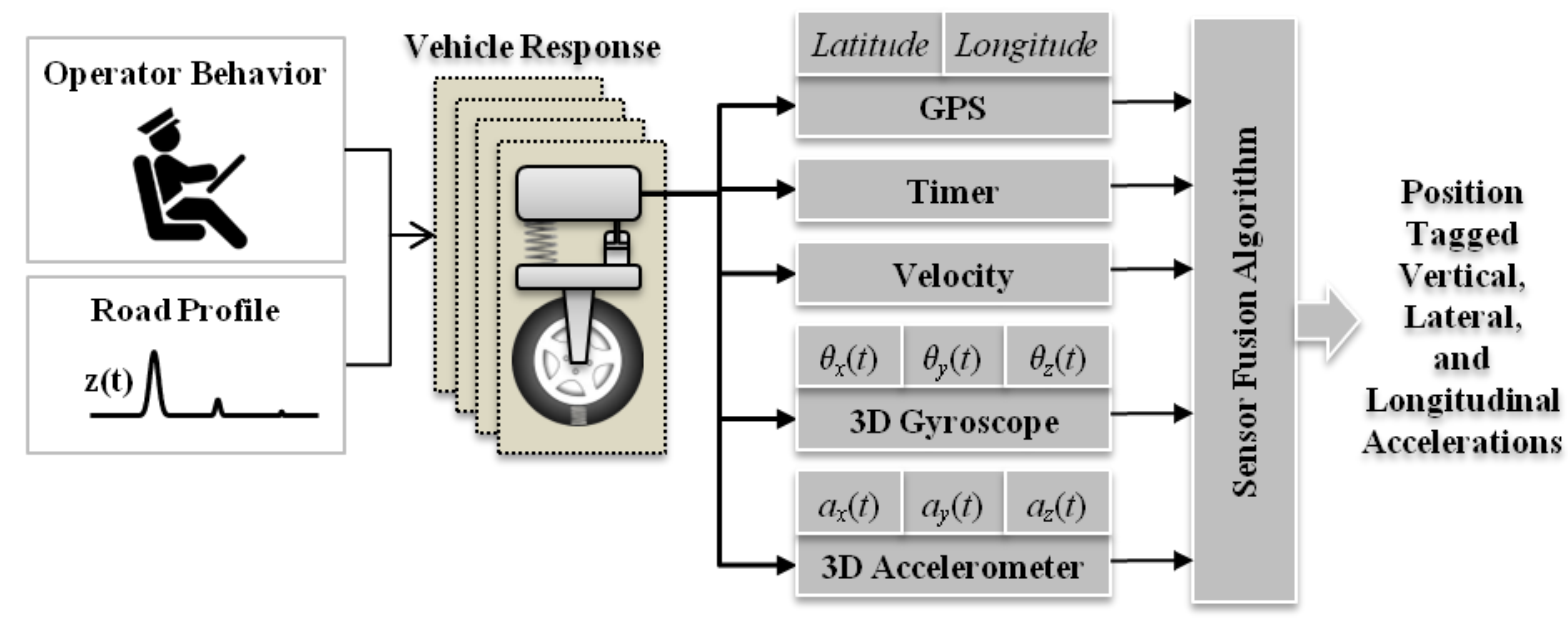

Figure 3.2 Overview of Roughness Measurements and the Data Processing

Operator behaviors such as braking and acceleration, and road surface conditions such as bumps and potholes excite the suspension systems of each wheel assembly. The forced and transient responses of the individual wheel assemblies produce vibrations in the lateral (x), longitudinal (y), and vertical (z) 
directions relative to the travel direction. The vehicle dynamic responses also contain rotations about the $\mathrm{x}-, \mathrm{y}-$, and $\mathrm{z}$-axis. Figure 3.3 illustrates the reference orientations when the front of the smartphone measuring device points in the direction of travel.

The resultant vertical acceleration is determined by multiplying the linear acceleration from each sensor axis $(\mathrm{x}, \mathrm{y}, \mathrm{z})$ by the magnitude of the respective directional components of a $\mathrm{z}$-unit vector rotated in the Cartesian plane by the measured pitch, roll, and yaw angles.

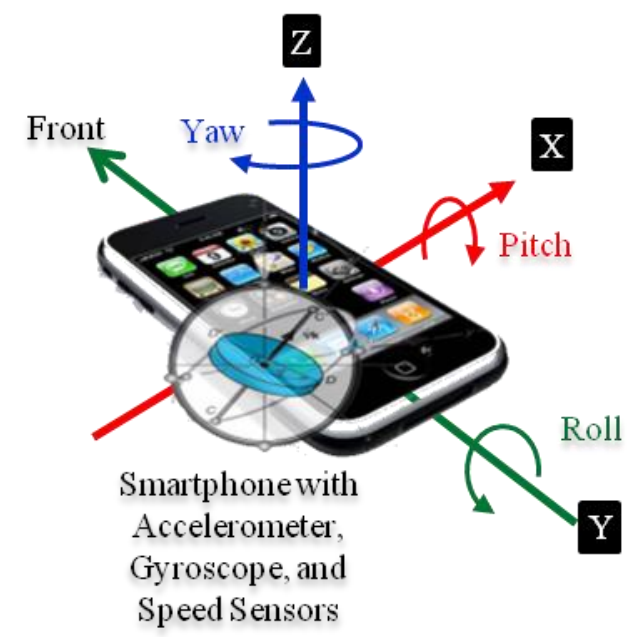

Figure 3.3 Reference Orientations for the Smartphone Data Collection Application

The rotation of a unit vector $\Pi_{x y z}$ is

$$
\Pi_{x y z}\left(u_{x y z}, \theta_{x}, \theta_{y}, \theta_{z}\right)=\left[\begin{array}{ccc}
1 & 0 & 0 \\
0 & \cos \left(\theta_{x}\right) & \sin \left(\theta_{x}\right) \\
0 & -\sin \left(\theta_{x}\right) & \cos \left(\theta_{x}\right)
\end{array}\right]\left[\begin{array}{ccc}
\cos \left(\theta_{y}\right) & 0 & -\sin \left(\theta_{y}\right) \\
0 & 1 & 0 \\
\sin \left(\theta_{y}\right) & 0 & \cos \left(\theta_{y}\right)
\end{array}\right]\left[\begin{array}{ccc}
\cos \left(\theta_{z}\right) & \sin \left(\theta_{z}\right) & 0 \\
-\sin \left(\theta_{z}\right) & \cos \left(\theta_{z}\right) & 0 \\
0 & 0 & 1
\end{array}\right] u_{x y z}
$$

where $\theta_{\mathrm{x}}, \theta_{\mathrm{y}}$, and $\theta_{\mathrm{z}}$ are the pitch, roll, and yaw angles produced by the gyroscope integrated in the smartphone. The z-unit vector $u_{\mathrm{z}}=\left[\begin{array}{lll}0 & 0 & 1\end{array}\right]^{T}$ and the unit vectors for the $\mathrm{x}$ and $\mathrm{y}$ directions are $u_{\mathrm{x}}=\left[\begin{array}{lll}1 & 0 & 0\end{array}\right]^{T}$ and $u_{\mathrm{y}}=\left[\begin{array}{lll}0 & 1 & 0\end{array}\right]^{T}$, respectively. The notation $T$ represents the vector transpose matrix operator. Therefore, the resultant vertical acceleration $g_{\mathrm{z}}$ as a function of the sensor orientation is

$$
g_{\mathrm{z}}\left(\theta_{\mathrm{x}}, \theta_{\mathrm{y}}, \theta_{\mathrm{z}}\right)=\sqrt{\left[a_{\mathrm{x}} \cdot \Pi_{\mathrm{xyz}}\left(u_{\mathrm{z}}, \theta_{\mathrm{x}}, \theta_{\mathrm{y}}, \theta_{\mathrm{z}}\right)_{\mathrm{x}}\right]^{2}+\left[a_{\mathrm{y}} \cdot \Pi_{\mathrm{xyz}}\left(u_{\mathrm{z}}, \theta_{\mathrm{x}}, \theta_{\mathrm{y}}, \theta_{\mathrm{z}}\right)_{\mathrm{y}}\right]^{2}+\left[a_{\mathrm{z}} \cdot \Pi_{\mathrm{xyz}}\left(u_{\mathrm{z}}, \theta_{\mathrm{x}}, \theta_{\mathrm{y}}, \theta_{\mathrm{z}}\right)_{\mathrm{z}}\right]^{2}}
$$

where $a_{\mathrm{xu}}, a_{\mathrm{yu}}$, and $a_{\mathrm{zu}}$ are the accelerations registered for the individual sensor axis and the subscript $z$ of the rotated vector is the vertical acceleration component. The resultant accelerations in the lateral and longitudinal directions are similarly obtained by multiplying the sensor values from the individual rotated accelerometers by the lateral and longitudinal components $x$ and $y$ respectively, of their rotated unit vectors. That is,

$$
g_{\mathrm{x}}\left(\theta_{\mathrm{x}}, \theta_{\mathrm{y}}, \theta_{\mathrm{z}}\right)=\sqrt{\left[a_{\mathrm{x}} \cdot \Pi_{\mathrm{xyz}}\left(u_{\mathrm{x}}, \theta_{\mathrm{x}}, \theta_{\mathrm{y}}, \theta_{\mathrm{z}}\right)_{\mathrm{x}}\right]^{2}+\left[a_{\mathrm{y}} \cdot \Pi_{\mathrm{xyz}}\left(u_{\mathrm{x}}, \theta_{\mathrm{x}}, \theta_{\mathrm{y}}, \theta_{\mathrm{z}}\right)_{\mathrm{y}}\right]^{2}+\left[a_{\mathrm{z}} \cdot \Pi_{\mathrm{xyz}}\left(u_{\mathrm{x}}, \theta_{\mathrm{x}}, \theta_{\mathrm{y}}, \theta_{\mathrm{z}}\right)_{\mathrm{z}}\right]^{2}}
$$


and

$$
g_{\mathrm{y}}\left(\theta_{\mathrm{x}}, \theta_{\mathrm{y}}, \theta_{\mathrm{z}}\right)=\sqrt{\left[a_{\mathrm{x}} \cdot \Pi_{\mathrm{xyz}}\left(u_{\mathrm{y}}, \theta_{\mathrm{x}}, \theta_{\mathrm{y}}, \theta_{\mathrm{z}}\right)_{\mathrm{x}}\right]^{2}+\left[a_{\mathrm{y}} \cdot \Pi_{\mathrm{xyz}}\left(u_{\mathrm{y}}, \theta_{\mathrm{x}}, \theta_{\mathrm{y}}, \theta_{\mathrm{z}}\right)_{\mathrm{y}}\right]^{2}+\left[a_{\mathrm{z}} \cdot \Pi_{\mathrm{xyz}}\left(u_{\mathrm{y}}, \theta_{\mathrm{x}}, \theta_{\mathrm{y}}, \theta_{\mathrm{z}}\right)_{\mathrm{z}}\right]^{2}}
$$

\subsubsection{Roughness Impact Factors}

The RIF, denoted $I_{\text {road }}^{L}$ includes accelerations from both the vertical and the lateral directions. Vertical accelerations result from traversing bumps and depressions along the road surface. Lateral accelerations tend to arises when only the left side or right side wheel assembles traverse from road surface unevenness. Hence, the RIF is the vector sum of the VRI and the LRI such that

$$
I_{\text {road }}^{L}=\sqrt{\left[R_{z}^{L}\right]^{2}+\left[R_{x}^{L}\right]^{2}}
$$

The mean RIF measured from traversing the entire roadway segment is

$$
\bar{I}_{x}^{L}=\frac{1}{K} \sum_{k=0}^{K-1} I_{x}^{L}[k]
$$

The DIF, denoted $I_{\text {driver }}^{L}$ integrates driver-induced accelerations and decelerations in the longitudinal direction. The operator may also introduce some gradual lateral acceleration by speeding around curves. However, the asymmetric wheel-path traversals of roadway unevenness tend to dominate the lateral accelerations. Therefore, the mean DIF is primarily the mean ORI such that

$$
\bar{I}_{\text {driver }}^{L}=\bar{R}_{y}^{L} \text {. }
$$

Subsequently, the TRQ, denoted $Q_{\text {ride }}^{L}$ is the vector sum of the mean RIF and the mean DIF such that

$$
Q_{\text {ride }}^{L}=\sqrt{\left[\bar{I}_{\text {road }}^{L}\right]^{2}+\left[\bar{I}_{\text {driver }}^{L}\right]^{2}}
$$

The VIF is a function of the vehicle types. Differences in their suspension system behaviour result in different amounts of roughness suppression of the RIF and DIF that produces the TRQ. Therefore, this research defines the VIF relative to a reference passenger sedan and driver. Subsequently, the VIF of a bus will be the ratio of the TRQ measured from the reference car traversals to the TRQ measured from the bus traversals across the same route, and under similar driving patterns of speeds and dwell times. The VIF is denoted as $I_{\mathrm{VIF}}^{L}$ and defined as

$$
I_{\mathrm{VIF}}^{L}=\frac{Q_{\text {ride }}^{L}(\text { ReferenceCar })}{Q_{\text {ride }}^{L}(\text { Buses })}
$$

With this formulation, it would be possible for transit agencies to determine the transit ride quality of any new test vehicle relative to that of a reference vehicle and driver of their choice. The reference vehicle may also be another bus that has known handling capabilities and suspension performance, and a trained operator with known behaviours. In general, an impact factor greater than unity would indicate that the 
test vehicle provides a smoother ride than the reference vehicle, with all other factors being equal. In other words, the reference vehicle selected should ideally represent an acceptable or desirable ride quality for a majority of the passengers.

\subsection{Data Collection and Processing Methods}

The case study will characterize the TRQ for at least two transit routes of distinctly different levels of roughness. A survey of the riders on those routes will reveal the relationship between their subjective perceptions of roughness and the objective levels measured. The survey will also reveal any influences from the actual roughness level experienced to the stated level of its importance.

\subsubsection{Setup for Data Collection}

The device used for data collection was an iPhone® 4 S. Figure 3.4 shows a top view of the smartphone installation on the bus. Figure 3.5 a illustrates a side view of the platform that held the smartphone in place.

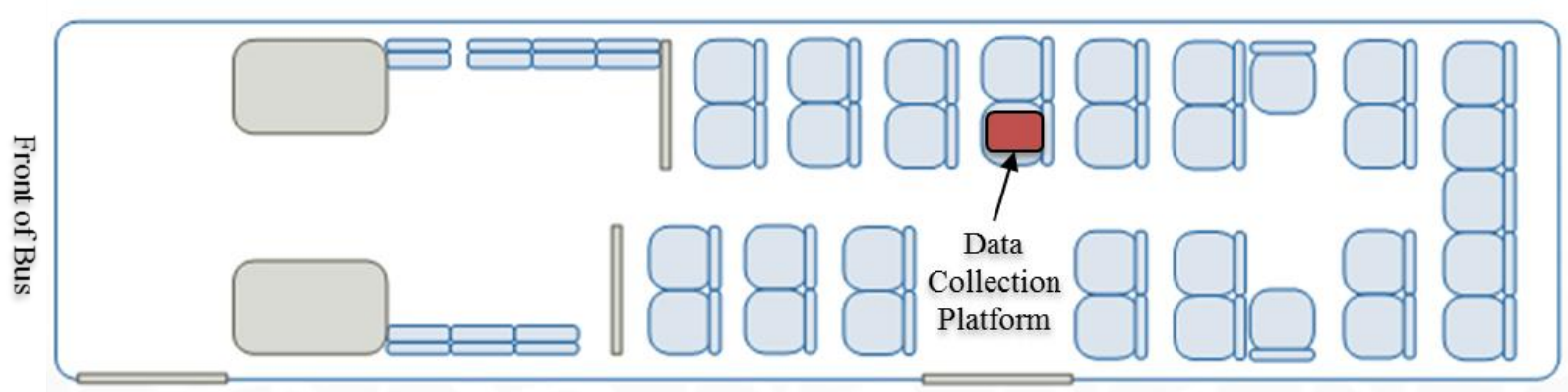

Figure 3.4 Top View of Data Collection Planform Installation on the Bus
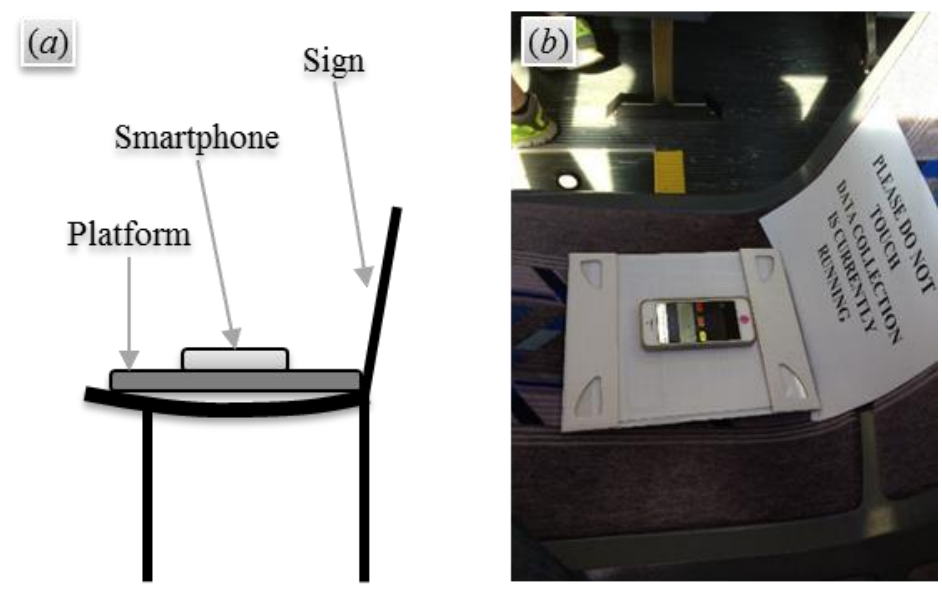

Figure 3.5 Data Collection Platform a) Arrangement and b) Picture of Setup

The device was positioned towards the center of the bus and on top of a passenger seat. Therefore, the device measured the roughness that a typical seated passenger would have experienced. While the bus was parked, the researchers used a leveling application on the smartphone to adjust the platform until it was flat. The front of the smartphone pointed in the direction of travel. Figure $3.5 \mathrm{~b}$ shows an actual 
installation. The sign on the seat back informed passengers that the roughness data collection was in progress.

Using the same device for all measurements obviated the need to characterize any gain errors of the embedded accelerometers. That is, obtaining a relative measure of roughness from the same device sufficed for these experiments. However, if future experiments use multiple smartphone devices, some effort should be incurred to characterize any differences in sensitivity or gain among the sensors of the data logging devices. Subsequently, any significant differences in sensor parameters should be accounted for in a calibration procedure.

A possible limitation of this installation is that it measures roughness from a nominal location near the center of the bus. Hence, these single point measurements may understate roughness that is more intense towards the front or rear of the bus, particularly at locations closer to the axles. Another possible limitation is the consistent vertical position of the sensor. Locating the device on the seat of a bus may adequately characterize the intensity of vertical accelerations but understate the effects of lateral or longitudinal accelerations induced closer to the rider's head. In particular, lateral accelerations from road disturbances such as potholes that impact only one side of the bus could produce lateral accelerations that result in head tossing. Subsequently, future experiments to more accurately characterize ride roughness should consider merging measurements from multiple vertical and horizontal sensor locations on the same bus.

\subsubsection{Tool for Data Collection}

The data collection app is called PAVVET. It is available from the Apple Store. The GPS receiver on the smartphone provided an update rate of $1 \mathrm{~Hz}$ and the accelerometer was set to sample at $128 \mathrm{~Hz}$ based on recommendations from prior studies (R. Bridgelall 2014). The app logged inertial and geospatial position data as the vehicle traversed the routes. Figure 3.6 is a screen shot of the app recording accelerometer, gyroscope, GPS, and timer data. 


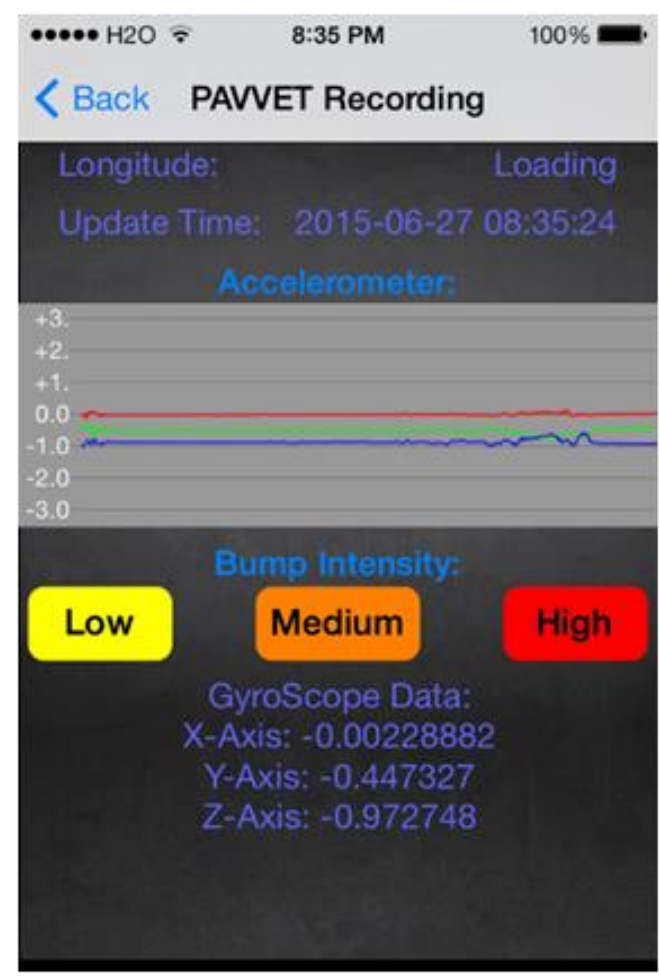

Figure 3.6 Screen Shot of the Smartphone Data Collection Application

The app produces output files in a comma separated value (CSV) file format that is organized as shown in Table 3.1.

Table 3.1 Format of the Smartphone Application Data Log

\begin{tabular}{llllllllll}
\hline Time & Gz & Lat & Lon & Vel & Pitch & Roll & Yaw & Gx & Gy \\
\hline 21.347 & -0.98 & 46.88096 & -96.7701 & 1.42 & 8.19 & 1.51 & -25.61 & 0.05 & -0.13 \\
23.956 & -1.02 & 46.88096 & -96.7701 & 1.42 & 8.17 & 1.51 & -25.63 & 0.05 & -0.14 \\
26.118 & -0.99 & 46.88096 & -96.7701 & 1.42 & 8.17 & 1.51 & -25.63 & 0.02 & -0.15 \\
37.812 & -1.03 & 46.88096 & -96.7701 & 1.42 & 8.17 & 1.50 & -25.64 & 0.05 & -0.12 \\
48.627 & -0.97 & 46.88096 & -96.7701 & 1.42 & 8.17 & 1.50 & -25.64 & 0.08 & -0.14 \\
59.410 & -1.02 & 46.88096 & -96.7701 & 1.42 & 8.16 & 1.55 & -25.67 & 0.00 & -0.16 \\
123.741 & -0.95 & 46.88096 & -96.7701 & 1.42 & 8.20 & 1.47 & -25.73 & 0.02 & -0.13 \\
134.777 & -1.05 & 46.88096 & -96.7701 & 1.42 & 8.20 & 1.47 & -25.73 & 0.04 & -0.15 \\
\hline
\end{tabular}

The first row contains a header with labels for each column of data sampled from the inertial and geospatial sensors on the smart phones. The integrated timer provides the "Time" data in milliseconds. The integrated GPS receiver provides the latitude $\left(\mathrm{L}_{\mathrm{at}}\right)$ and longitude $\left(\mathrm{L}_{\mathrm{on}}\right)$ data in decimal format, and the ground speed $\left(\mathrm{G}_{\text {speed }}\right)$ in $\mathrm{m} / \mathrm{s}$. The integrated inertial sensor provides the accelerator values for the $\mathrm{g}$-forces sensed in the vertical, lateral, and longitudinal directions as " $\mathrm{G}_{\mathrm{z}}$ ", " $\mathrm{G}_{\mathrm{x}}$ ", and " $\mathrm{G}_{\mathrm{y}}$ ", respectively and normalized to $9.81 \mathrm{~m} / \mathrm{s}^{2}$. The integrated gyroscope produces the "Pitch," "Roll," and "Yaw" for the sensor orientation angles in degrees, respectively. 


\subsubsection{Data Processing}

After data collection via the smartphone app, the researcher taps a screen icon to upload the logged files to a server. The app utilizes any of its available wireless connection to communicate with a server. The universal resource locator (URL) for the server is entered in the app setup screen. After the raw data files become available on the server, offline processing utilizes Equations (1) to (3) to generate the directional roughness indices (VRI, LRI, ORI). Figure 3.7 illustrates the data flow, the computational process, and some details of the procedure that calculates the directional roughness indices. Future versions of the app will integrate the offline portion of the computational process so that the app could directly display the ride quality indices during data collection process.

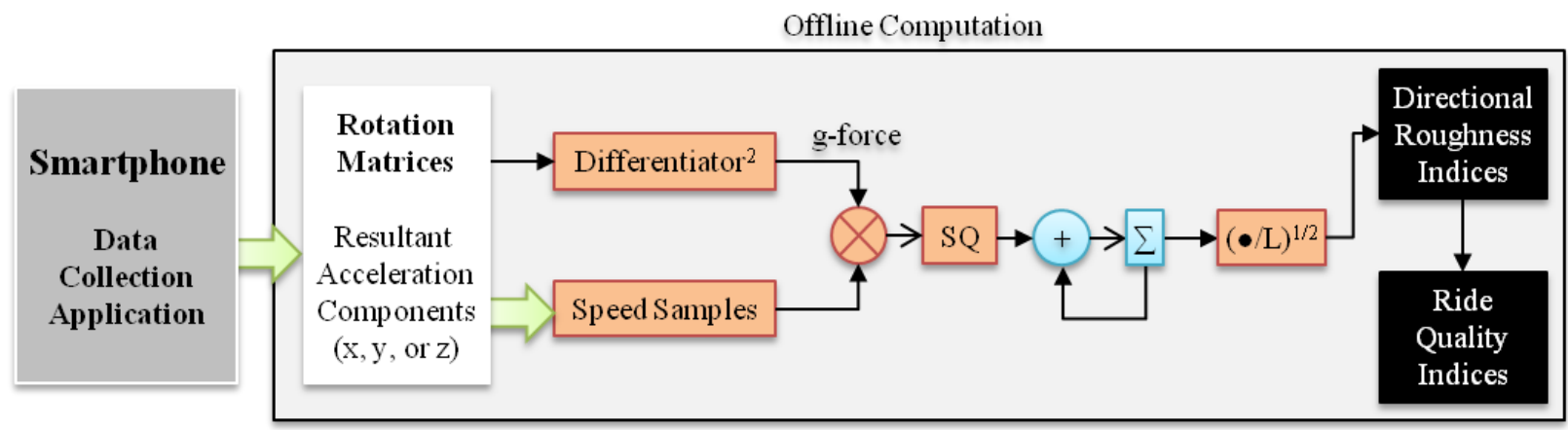

Figure 3.7 Calculation Procedure to Produce the Directional Roughness and Ride Quality Indices

Figure $3.8 \mathrm{a}$ is a plot of the of the directional roughness indices for consecutive 10-meter sections of a relatively smooth sample segment.

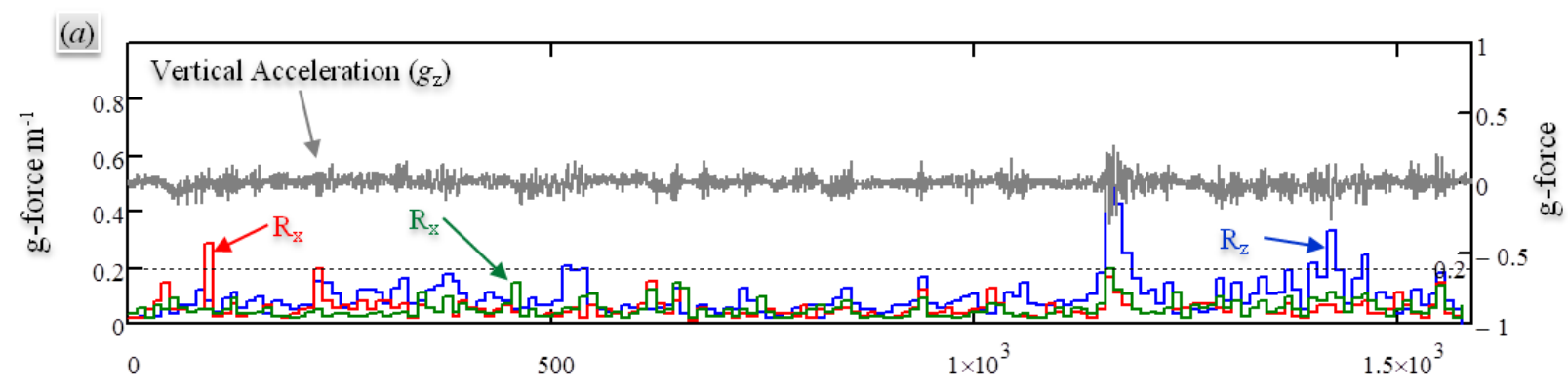

(b)

Distance (meters)

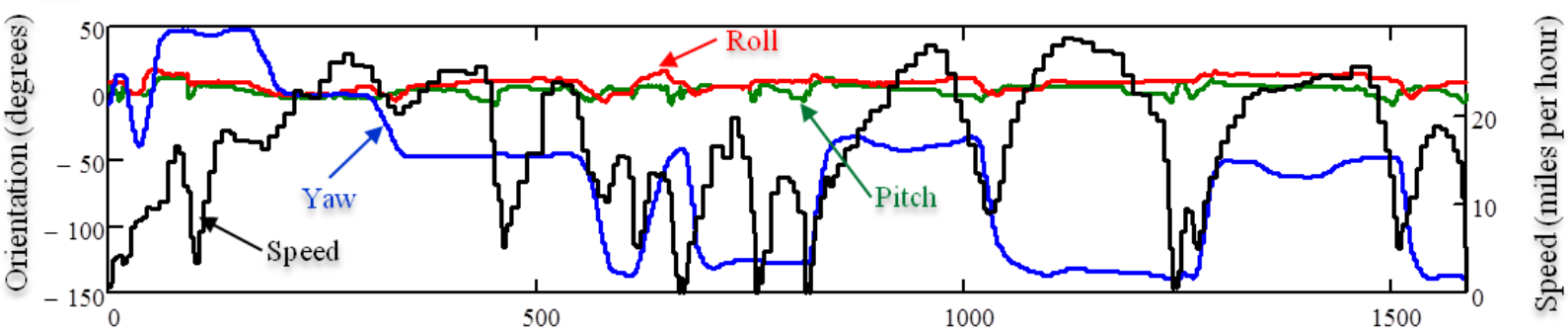

Distance (meters)

Figure 3.8 Data Sample from a Relatively Smooth Ride 
The directional roughness indices are referenced to the left axis. The vertical acceleration data samples, $g_{z}$ are shown for comparison. Those signal samples are referenced to the right axis of the chart. It is evident that the directional roughness transform integrates many acceleration samples to produce a single index summary of the roughness experienced across the 10-meter segments of the traversal path. As this study focuses on summarizing roughness that a passenger experiences between their entry and exit stops, the analysis will use the mean of the RIFs and DIFs derived from their respective 10-meter directional roughness indices. The remainder of this document will refer to the mean of the 10-meter RIFs and DIFs as simply the traversal RIF and DIF, respectively. Statistically, each traversal will produce a different mean RIF and mean DIF.

Figure $3.8 \mathrm{~b}$ is a plot of the orientation changes sensed and the longitudinal speed of the vehicle in miles per hour (MPH). As previously described, the rotation model of Equation (5) utilizes these roll, pitch, and yaw values to compute the three directional accelerations of each sample. The directional roughness transforms use the instantaneous speed samples to compute the directional roughness indices. In this application, the speed sensor updated the speed at a rate of 1 Hertz. An ability to use the speed sensor directly from the vehicle's information bus, as in a connected vehicle application, will produce even more accurate characterizations of roughness (R. Bridgelall 2015). To visually compare the magnitudes of directional roughness indices, Figure 3.9a plots them for a relatively rough segment. It is clear that the directional roughness indices, particularly for the vertical direction, are on average larger in magnitude for the rough segment. The speed changes indicate the acceleration and deceleration patterns of the bus as it traverses the segment.
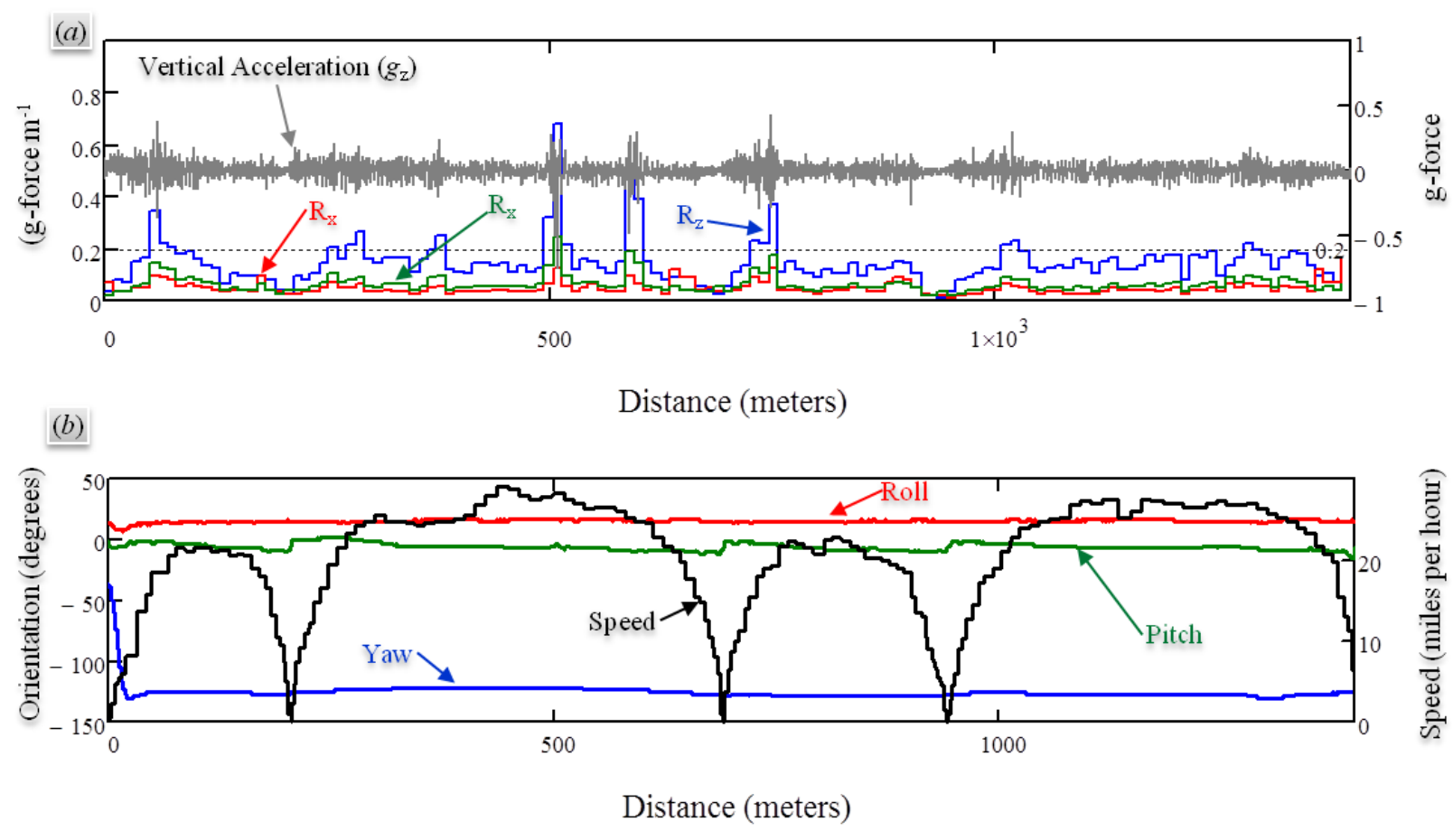

Figure 3.9 Data Sample from a Relatively Rough Ride 


\subsubsection{Statistical Characterizations}

Statistical distributions of the RIF- and DIF-indices obtained for each route segment is tested for a fit with the Gaussian and Student- $t$ distributions (Agresti and Finlay 2009). Scale and translation parameters are introduced into each normalized distribution to best fit a histogram of the RIF- and DIF-indices. The Gaussian model $D_{g}(\xi)$ estimates the distribution of a variable $\xi$ such that

$$
D_{g}(\xi)=\frac{\alpha_{g}}{\sqrt{2 \pi \sigma_{g}^{2}}} \exp \left[-\frac{1}{2}\left(\frac{\xi-\mu_{g}}{\sigma_{g}}\right)^{2}\right]
$$

where $\alpha_{g}, \mu_{g}$, and $\sigma_{g}$ are estimates of the amplitude, mean, and standard deviation parameters, respectively. Similarly, the modified Student's $t$-distribution $D_{t}(\xi)$ is

$$
D_{t}(\xi)=\frac{\alpha_{t}}{\sigma_{t}} t_{d f}\left[\frac{\xi-\mu_{t}}{\sigma_{t}}\right]
$$

where $t_{d f}(\xi)$ is the normalized Student's $t$-distribution, which is a gamma function of $\xi$ and $d f$ degrees of freedom. The parameters $\alpha_{t}, \mu_{t}$, and $\sigma_{t}$ are estimates of the amplitude, mean, and standard deviation parameters, respectively.

To test the distribution fit, the chi-squared value $\left(\chi^{2}\right.$ Data $)$ is calculated as

$$
\chi^{2}=\sum_{k=1}^{n} \frac{\left(O_{k}-E_{k}\right)^{2}}{E_{k}}
$$

where $O_{k}$ are histogram values observed in bin $k$ and $E_{k}$ are the expected values from the hypothesized distribution. The chi-squared distribution value for 5\% significance $(\alpha=5 \%)$ is the largest value expected within $95 \%$ of the cumulative distribution. Hence, the significance percentage is the probability of observing a chi-squared value at least as large as the value computed from Equation (16). The chi-squared degrees of freedom, $d f$, are determined as one less than the number of histogram data elements $n$, minus the two independent distribution parameters estimated, namely the amplitude and the standard-deviation, the latter being dependent on the estimate of the mean.

To assess the adequacy of the sample size (Agresti and Finlay 2009), the experiments computes the margin-of-error (MOE) for a (1- $\alpha) \%$ confidence interval with significance $\alpha$ where

$$
M O E_{1-\alpha}=\frac{\sigma_{t} \times t_{1-\alpha / 2, d f}}{\sqrt{N_{v}}}
$$

The variable $N_{v}$ is the sample size, which is the traversal volume in these experiments. The variable $t_{1-\alpha / 2, d f}$ is the $t$-value where the cumulative $t$-distribution of $d f$ degrees of freedom evaluates to (1- $\alpha$ ). The literature generally recommends a sample size of at least 30 for statistical significance (Agresti and Finlay 2009). If statistical tests cannot reject a hypothesis that the data is normally distributed, then increasing the sample sizes will tend to further reduce the MOE. This is anticipated from equation (17) because the sample size is in the denominator. 


\subsection{Survey of Riders}

The main objectives of the survey were to characterize the importance of ride smoothness to bus users, and to determine their potential for selecting alternative transportation options when a ride is considered too rough. Another objective was to assess the subjective ratings of ride roughness for each of the segments, and to compare those ratings with the objective measurements.

\subsubsection{Institutional Review Board (IRB) Compliance}

This research method complied with the standard Institutional Review Board (IRB) procedures for a category 2 exemption. All researchers on the team completed the required IRB training. Hence, the survey did not collect any identifying information about the passengers. In fact, the approval process required that the back side of the survey contain the informed consent statement shown.

\subsubsection{Design of Survey Instrument}

The design of the survey focused on a few simple questions to encourage patron's willingness to complete it within 5 minutes while riding the short segments. Therefore, there were only 5 questions as illustrated in Figure 3.10. The first question asked bus passengers to circle their description of the ride. The qualitative descriptors were "very smooth," "smooth," "neutral," "rough," and "very rough." This question intended to elicit a subjective rating of the roughness experienced while riding the segment of the bus route.

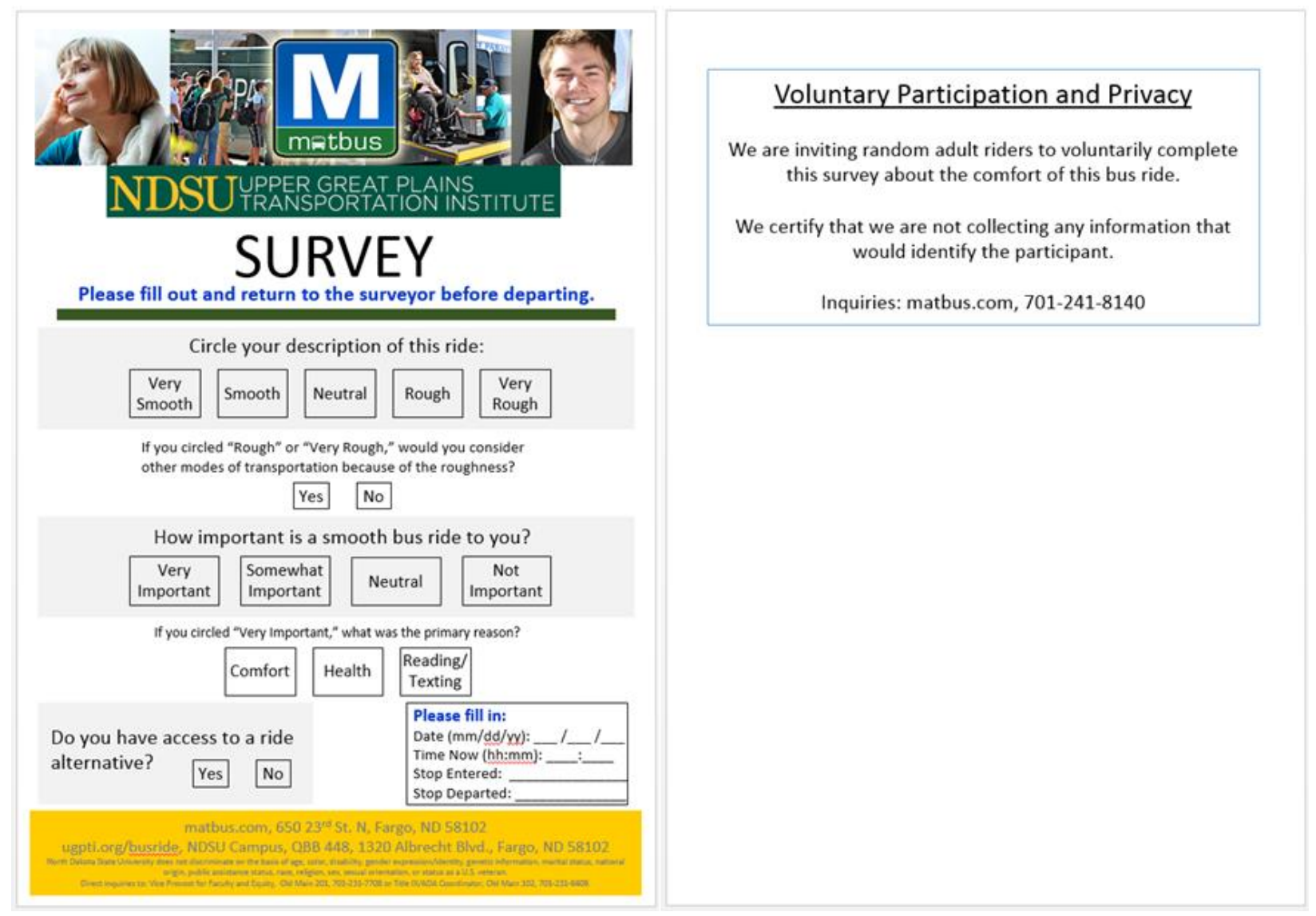

Figure 3.10 Front and Back Side of the Survey Card Used in the Study 
The second question intended to determine the proportion of riders who would consider other modes of transportation because they felt that the bus ride was too rough. The next two questions intended to determine the level of importance of a smooth ride and, when considered very important, their primary reason. This question also helped to isolate the specific disutility of a rough ride for bus users who would consider other modes of transportation because the ride is too rough.

The final question intended to reveal the proportion of bus users who were captive riders for each segment, and the degree of opportunity for the city to retain or increase the frequency of passengers choosing bus mode.

\subsubsection{Execution of Survey}

To adequately cover the ridership characteristics of each route, the researchers conducted surveys during different parts of the day, and over a three-month period lasting from October 2015 to December 2015. The research assistant (RA) distributed surveys during the morning, midday, and afternoon services for each bus route. To best normalize other conditions of the bus ride, there were no surveys conducted with ground precipitation from rain or snow. There were no significant service changes or incidents during the surveys. Therefore, it is possible that the consistency of the ride conditions may have influenced perceptions of ride smoothness. Hence, one limitation of this study is that it does not examine the degree of any possible correlation between other convenience factors and the perception of ride smoothness.

To setup the roughness measurement apparatus and to prepare for conducting the survey, the RA entered the bus while it was parked. Upon arriving at the beginning of each segment, the RA randomly invited passengers to complete the survey and stopped after two to three passengers committed to return responses before they disembarked. When a passenger returned the completed survey, the RA ensured that all of the information was filled out, including the time, date, stop entered, and stop exited. The RA then annotated the survey with the route and bus number. Upon completion of the route, the RA entered the survey information into a spreadsheet by coding the responses numerically. 


\section{CASE STUDY}

The research team partnered with the Fargo Transit Administration of the City of Fargo to measure the ride quality on the MATBUS public transportation system and to conduct surveys of their bus riders. The next sections describe the route selections and the segments tested, the vehicles used for the case study, and the methods of data collection and data processing.

\subsection{Routes Selected}

The case study included four segments from two bus routes that serve the South Fargo and West Fargo areas of North Dakota. Two of the segments overlapped to allow for comparison of objective and subjective assessments of the ride quality. Figure 4.1 illustrates the bus routes and highlights the four analysis segments labeled S1, S2, S3, and S4 at their starting points. The routes terminate at two transfer points where passengers can take other buses. One of the transfer points is called the Ground Transportation Center (GTC), which is a bus terminal that facilitates connections to 11 bus routes that service residential and business regions around Fargo. The second transfer point is a bus hub at the Mall that facilitates connections among four other routes. As a reference, the North Dakota State University (NDSU) and the Fargo downtown area are two of the largest attraction points in Fargo, and they are located a few miles northwest of the GTC.

Segment 3 is a 1.4-mile section of route 15 that begins at a stop located near the intersection of $13^{\text {th }}$ avenue and University Drive, and ends at the GTC bus terminal. This segment overlaps with segment 2 for a majority of the bus ride. The average travel time for segment 2 was 6 minutes. Survey respondents for segment 3 entered the bus at prior stops that include the Mall.

Segment 4 is a 2.4-mile loop of route 15 that begins at the mall and has intermediate stop on the way to Wal-Mart (WMT) and back. The average travel time for the Mall-WMT loop was 14 minutes. Survey respondents for segment 4 entered the bus at prior stops that include the GTC. Hence, they may have transferred from other buses on their way to WMT.

Table 4.1 lists the length and average travel time of the four analysis segments. Segment 1 is a 3.2-mile section of route 14 that begins at a stop near Essentia Hospital (EH) and ends at the Mall bus hub. The average travel time for segment 1 was 12.3 minutes, including traffic, stop signs, traffic lights, and other flow interruptions. Survey respondents entered the bus at the EH or at prior stops near businesses such as the Family Fare supermarket, K-Mart, the YMCA, Hornbachers Supermarket, or residences near University Drive and $32^{\text {nd }}$ avenue.

Segment 2 is a 1.3-mile section that is also part of route 14. The segment begins at a stop before the intersection of $13^{\text {th }}$ avenue and University Drive, just north of Sanford Hospital (SH). It ends at the GTC bus terminal. The average travel time for segment 2 was 5.7 minutes. Survey respondents entered the bus at prior stops that include the Mall. 


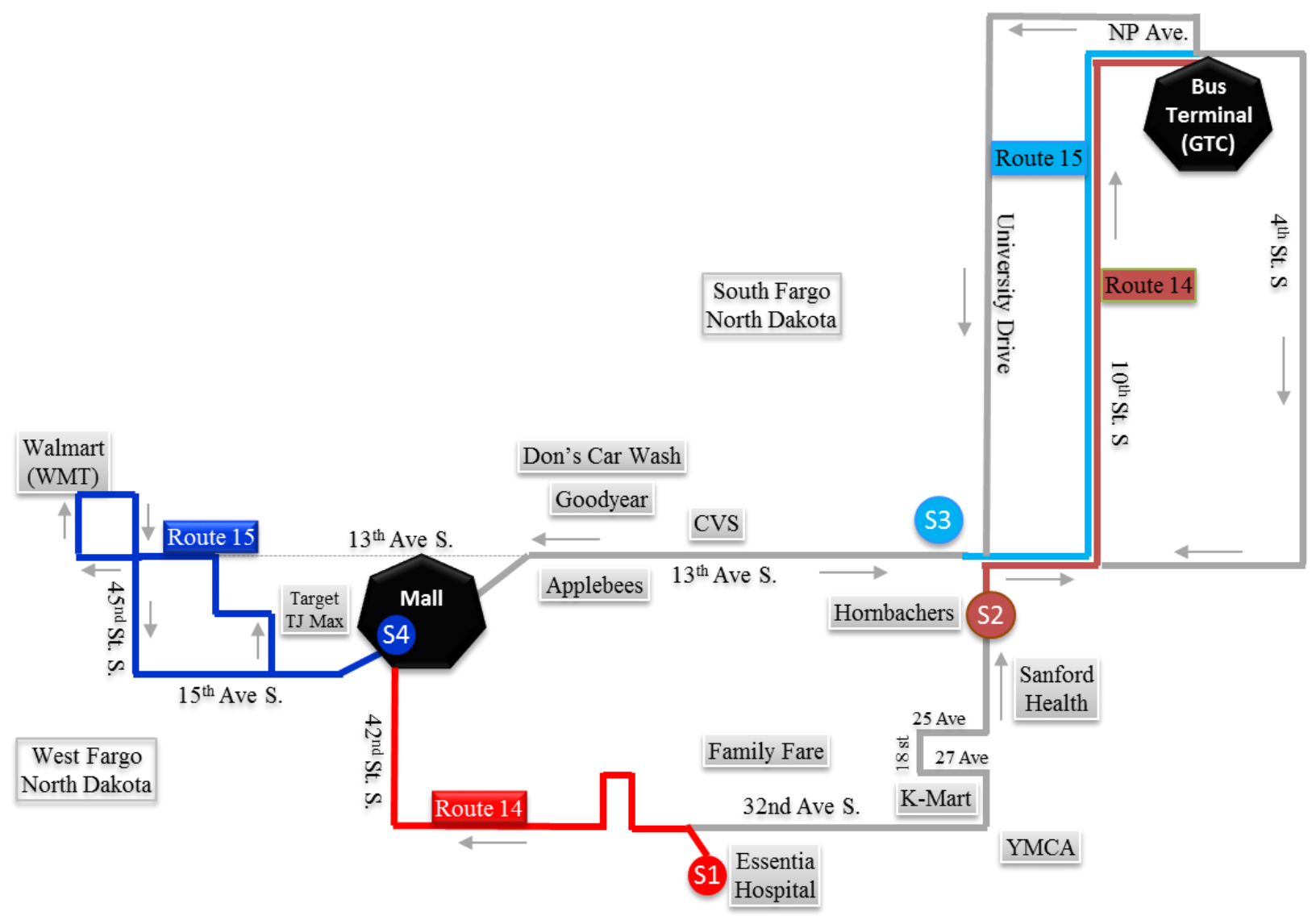

Figure 4.1 Overview of the Ride Segments Selected and the Bus Routes

Segment 3 is a 1.4-mile section of route 15 that begins at a stop located near the intersection of $13^{\text {th }}$ avenue and University Drive, and ends at the GTC bus terminal. This segment overlaps with segment 2 for a majority of the bus ride. The average travel time for segment 2 was 6 minutes. Survey respondents for segment 3 entered the bus at prior stops that include the Mall.

Segment 4 is a 2.4-mile loop of route 15 that begins at the mall and has intermediate stop on the way to Wal-Mart (WMT) and back. The average travel time for the Mall-WMT loop was 14 minutes. Survey respondents for segment 4 entered the bus at prior stops that include the GTC. Hence, they may have transferred from other buses on their way to WMT.

Table 4.1 Routes and their Characteristics

\begin{tabular}{ccccc}
\hline Segment & Label & $\begin{array}{c}\text { Distance } \\
\text { (miles) }\end{array}$ & $\begin{array}{c}\text { Travel Time } \\
\text { (Minutes) }\end{array}$ & Description \\
\hline 1 & R14 EH-Mall & 3.2 & 12.3 & Route 14 from Essentia Hospital to the Mall \\
2 & R14 SF-GTC & 1.3 & 5.7 & Route 14 from Sanford Hospital to the GTC \\
3 & R15 13a-GTC & 1.4 & 6 & Route 15 from $13^{\text {th }}$ avenue to the GTC \\
4 & R15 WMT-Loop & 2.4 & 14 & Route 15 from the Mall to Wal-Mart and back \\
\hline
\end{tabular}




\subsection{The Test Vehicles}

The MATBUS agency deployed a mix of diesel and hybrid buses manufactured by GILLIG Corporation and New Flyer Industries (Figure 4.2). The bus passenger capacity ranged from 30 to 80 . The spread in ride quality is expected to increase with the number of different buses used, and also potentially with weight differences due to loading differences. All segments used 9 different buses except for the second segment which used 12 buses. During the time of the surveys, the typical bus carried less than half of its capacity of passengers for all traversals and all routes. Therefore, the bus loads were consistent and similar. As part of their normal operations, the transit agency assigned some of the same buses to each of the different segments throughout the data collection period. Incidentally, this mixed bus assignment helped to further randomize the data and remove any potential bias in the VIF when measuring the roughness indices on different segments. Table 4.2 lists the bus number identifiers for the buses deployed on each segment.
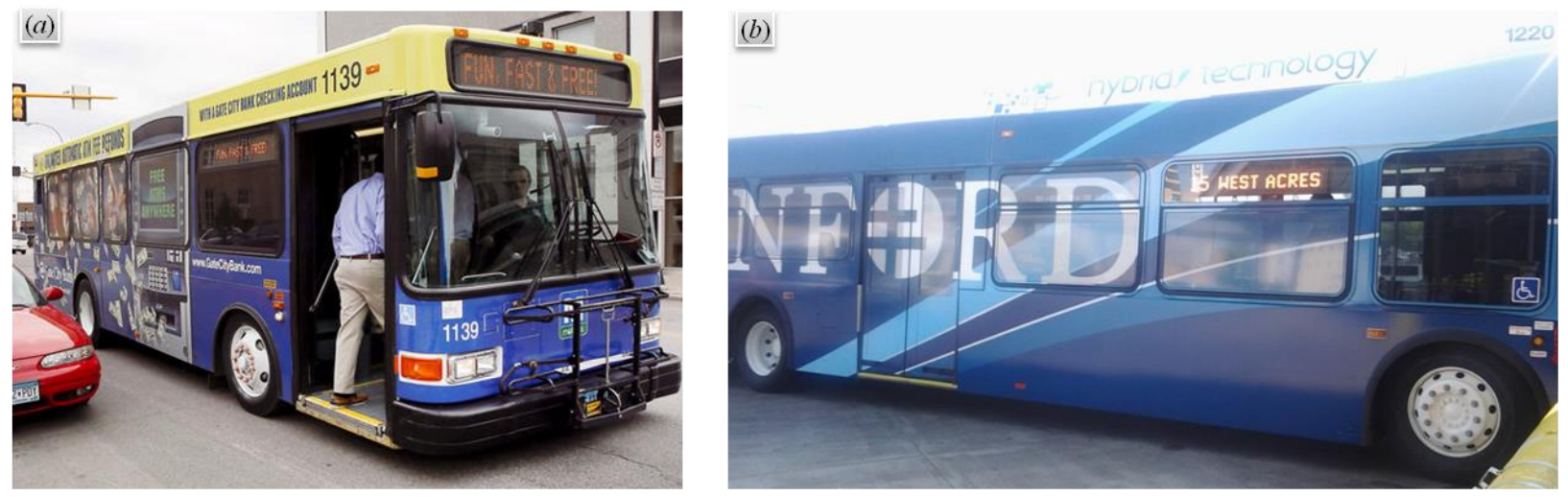

Figure 4.2 Sample of the Buses used in the Case Study (Courtesy: Matbus.com)

For a case study to establish a VIF for the buses, the research staff used a 2005 Pontiac Grand Prix as the reference sedan. The selection was based purely on cost, convenience, and availability. With an extended project scope and time, the authors envision future research that would investigate a variety of criteria for selecting reference vehicles. Transportation agencies will be important partners in such research. For example, some agencies may elect to use a particular bus based on additional ride quality survey responses, or based on bus manufacturer or independent third-party tests.

For a limited ride quality comparison among possible reference sedans, the authors also selected a slightly newer sedan. It was a 2014 Dodge Avenger and the data collected was substantially less. To maintain DIF consistency, the same driver operated both reference sedans across all routes. He also attempted to approximate the speed profile of the buses that traversed each test segment.

Table 4.2 Buses Deployed on each Segment

\begin{tabular}{cll}
\hline Segment & Label & Bus Identifiers \\
\hline 1 & R14 EH-Mall & $1126,1139,1140,1142,1175,1176,1185,1195,1199$ \\
2 & R14 SF-GTC & $1126,1127,1139,1140,1142,1174,1175,1176,1185,1195,1198,1199$ \\
3 & R15 13a-GTC & $1125,1126,1176,1198,1200,1201,1220,1221,1124$ \\
4 & R15 WMT-Loop & $1125,1126,1176,1198,1200,1201,1220,1221,1124$ \\
\hline
\end{tabular}




\subsection{Data Collection and Processing}

Statisticians commonly recommend a sample size greater than 30 to compare histograms with a Gaussian distribution (Agresti and Finlay 2009). Therefore, the RA collected data for 31 trips across each of the four segments. Some survey respondents entered cross streets or landmarks as their exit stops. Therefore, when entering transferring the survey data to a spreadsheet, the RA translated the information entered to the code selected for identifying each bus stops.

The data processing included the following manual steps:

1. Rename all data files with their date and timestamp. After the app uploaded the files, the receiving server timestamped them with the time of receipt. Therefore, this step helped to later identify data collection files in the time order that the app recorded them. Cross referencing time stamps helped to match the data collection time to the passenger survey times.

2. Produce the directional roughness indices from each traversal. This step required software to execute the directional roughness transforms, to generate the plots, and to verify the route by examining the trajectory from the GPS receiver output on a map.

3. Match the survey response to the directional roughness index measured. This step required integrating the directional roughness indices between the starting point of the segment, and the stop where the survey respondent disembarked the bus. Calculating the roughness that each survey respondent actually experienced was important for assuring the accuracy of the experiment. 


\section{RESULTS AND DISCUSSIONS}

This section establishes the ridership characteristics of each route and provides details of the objective roughness measurements. The first subsection reports on the perceptions of the ride quality and characterizes its level of importance to the transit users. The second subsection establishes statistics of the ride quality measured for the buses and for a reference sedan. The third subsection compares statistics of the total ride quality ratio for the buses and two reference sedans to establish the bus VIF. The final subsection compares the perception of roughness relative to the objective measurements.

\subsection{Ridership Characteristics}

This section reports on the survey results for each route. In general, the surveys revealed that the bus users are mostly captive and that ride smoothness is important primarily for comfort. The objective measures of roughness revealed that segment 1 is the roughness, followed by segments 2,3 and 4 . The next sections provide a details.

\subsubsection{Mostly Captive Riders}

There were a total of 334 surveys returned. Table 5.1 summarizes the sample sizes for each segment. The table also lists the proportion of bus users who has access to transportation alternatives for each of the segment. The results indicate that a majority (approximately 82\%) of the users across the evaluated routes are captive riders. However, a noteworthy proportion (18\%) of the riders has access to alternative modes of transportation.

Table 5.1 Portion of the Bus Passengers with Access to Ride Alternatives

\begin{tabular}{ccc}
\hline Segment & Samples & Has Alternative \\
\hline 1 & 76 & $23.68 \%$ \\
2 & 75 & $16.00 \%$ \\
3 & 76 & $19.74 \%$ \\
4 & 107 & $12.15 \%$ \\
\hline Mean & & $17.89 \%$
\end{tabular}

The next section (Table 5.5) establishes that the average measures of roughness decreases uniformly from segment 1 to segment 4 . From the survey, the roughest route had the most users (nearly 25\%) with access to a ride alternative at, whereas the smoothest route had the fewest (approximately 12\%). This suggests that the ridership impact would be significant if users select alternative modes because the ride is too rough. Therefore, programs that encourage mode shift to bus transit would also likely retain non-captive riders.

\subsubsection{Ride Smoothness Matters}

Ride smoothness mattered to a majority (nearly 63\%) of the bus users across all routes. As listed in Table 5.2, those included responses where a smooth ride is either "very important" or "somewhat important." Ride smoothness did not matter for only about approximately $9 \%$ of the passengers. A smooth ride was of neutral value for the remainder of the users. The proportion for which ride smoothness mattered increased from $50 \%$ to $69.2 \%$ as the measured route roughness decreased. This phenomenon suggests that as bus users become acclimated to the smoother ride, their perception of riding on rougher routes will become less favorable. For example, riders become more aware of jolts and bounces that are sudden or infrequent. The high level of importance of ride smoothness combined with the fact that the roughest route had the 
highest proportion of users (24\%) with ride alternatives suggests that programs aimed at ride quality enhancements could potentially result in a greater proportion of frequent-riders.

Table 5.2 Importance Level for a Smooth Ride

\begin{tabular}{|c|c|c|c|c|c|c|}
\hline \multirow[b]{2}{*}{ Route } & \multicolumn{4}{|c|}{ Importance Level } & \multicolumn{2}{|c|}{ Smoothness } \\
\hline & Very & Somewhat & Neutral & Not & Matters & Doesn't Matter \\
\hline 1 & $19.74 \%$ & $30.26 \%$ & $36.84 \%$ & $13.16 \%$ & $50.00 \%$ & $13.16 \%$ \\
\hline 2 & $22.67 \%$ & $38.67 \%$ & $28.00 \%$ & $10.67 \%$ & $61.33 \%$ & $10.67 \%$ \\
\hline 3 & $31.58 \%$ & $39.47 \%$ & $22.37 \%$ & $6.58 \%$ & $71.05 \%$ & $6.58 \%$ \\
\hline 4 & $25.23 \%$ & $43.93 \%$ & $24.30 \%$ & $6.54 \%$ & $69.16 \%$ & $6.54 \%$ \\
\hline & & & & & $62.89 \%$ & $9.24 \%$ \\
\hline
\end{tabular}

\subsubsection{Users Emphasize Ride Comfort}

For each route Table 5.3 lists the portions of users reporting the reasons that smoothness matter. Across all routes, the desire for ride comfort was the primary reason (nearly 75\%) that ride smoothness mattered. The ability to read and/or text message ranked second at approximately $22 \%$. Riders reported health as a reason only for the second route.

Table 5.3 Reason for Smoothness Being Very Important

\begin{tabular}{clll}
\hline \multicolumn{4}{c}{ Reason Smooth Very Important } \\
\hline Route & Comfort & Health & Read/Text \\
\hline 1 & $80.00 \%$ & $0.00 \%$ & $20.00 \%$ \\
2 & $58.82 \%$ & $11.76 \%$ & $29.41 \%$ \\
3 & $75.00 \%$ & $0.00 \%$ & $25.00 \%$ \\
4 & $85.19 \%$ & $0.00 \%$ & $14.81 \%$ \\
\hline Mean & $74.75 \%$ & $2.94 \%$ & $22.31 \%$
\end{tabular}

The second route is the only one where a significant proportion of the riders reported that health is a reason for ride smooth importance. This is perhaps not surprising because the route starts at a major healthcare park that hosts the facilities of Sanford Health, Essentia Hospital, and various other medical offices. It is well known that vibration exposure, for example, from riding farming equipment such as tractors has been linked to chronic back pain and low back symptoms (Mayton, et al. 2008). Therefore, it is possible that some riders who board the bus at that location were concerned about the physiological effects of roughness on the condition for which they sought medical services.

\subsubsection{The Utility of Ride Comfort}

For each route Table 5.4 lists the proportions of users who would consider other modes because the ride was too rough. It is evident that a majority of the bus users (79\%) who perceived the ride to be "rough" would not consider other modes of transportation because of the roughness. However, a noteworthy proportion (approximately 21\%) would consider other modes because of the roughness. Of that group, there were no responses that a smooth ride was "Not Important," thus validating that roughness was a significant factor in their response. 
Table 5.4 Portion of the Bus Riders Who Would Consider Other Modes

\begin{tabular}{ccc}
\hline Route & No & Yes \\
\hline 1 & $78.57 \%$ & $21.43 \%$ \\
2 & $85.71 \%$ & $14.29 \%$ \\
3 & $100.00 \%$ & $0.00 \%$ \\
4 & $100.00 \%$ & $0.00 \%$ \\
\hline
\end{tabular}

Secondly, the proportion who would consider other modes diminished rapidly as the measured route roughness decreased. Thirdly, the roughest segment has the least captive riders. These three findings provide strong evidence that roughness is a significant factor in the sustainability of selection bus transit, and probably also in mode shift to bus transit.

\subsection{Roughness Measurements}

This section characterizes the statistics of the roughness measurements across each of the four segments. The histogram plots for all bus traversals and those of the reference sedan are tested against a Gaussian distribution. The tests assess the measurement consistency to establish the margin-of-error within which the mean will converge with increasing traversal volume.

\subsubsection{Bus Data}

Figure 5.1a and Figure 5.1b plots histograms of the mean bus RIFs and DIFs, respectively, for all traversals of each of the segments. The least-squares fit of Gaussian distributions overlay the histograms for visual comparison. Table 5.5 and Table 5.6 lists the associated parameters for the fitted distributions of the RIFs and DIFs, respectively. The tables also list the statistics of the data, including the means, standard deviations (Std. Dev.) and margins-of-error in the 95\% confidence interval (MOE 95 ).

Statisticians generally reject a null hypothesis that the data follows a tested distribution if the significance level at the computed chi-squared value ( $\chi^{2}$ Data) is less than 5\%, or equivalently, if the computed chisquared value calculated from Equation (16) is greater than the theoretical chi-square distribution value at a 5\% significance level. It is evident that for all of the RIF distributions tested, the computed chi-squared values are substantially smaller than the theoretical chi-squared values at $5 \%$ significance. In fact, the significance percentages are substantially greater than 5\%; they ranged from $22.5 \%$ to $48.4 \%$. The test results are similar for the DIF distributions. The segment 1 DIF distribution produced a fairly narrow spread within only three bins. Hence, the $d f$ was insufficient to complete a chi-squared test. However, the significance of the tests for the DIF distributions of the remaining segments ranged from $34.5 \%$ to $58.6 \%$, which is much greater than 5\%. Therefore, the hypothesis that the distributions are Gaussian cannot be rejected. Subsequently, this result provides a high degree of confidence in the data quality, and that the variance of their mean will diminish with higher levels of vehicle traversals.

Table 5.5 shows a decrease in the RIF from segment 1 to segment 4 . The RIF for the roughest segment was $0.178 \mathrm{~g}$-force $\mathrm{m}^{-1}$ and that of the smoothest segment was $0.138 \mathrm{~g}$-force $\mathrm{m}^{-1}$. The $\mathrm{MOE}_{95}$ is below $9 \%$ for this relatively small data set, thereby indicating a high consistency in the traversals and the measurements. The measurements from segments 1, 3, and 4 exhibited an $\mathrm{MOE}_{95}$ that was less than 5\% on average. Segment 2 exhibited the largest $\mathrm{MOE}_{95}$. However, this is anticipated because there were 12 buses versus 9 for the other segments. Table 5.6 shows that the mean DIF-indices are consistent across all segments. This result indicates that all of the operators handled their vehicles in a consistent manner. 

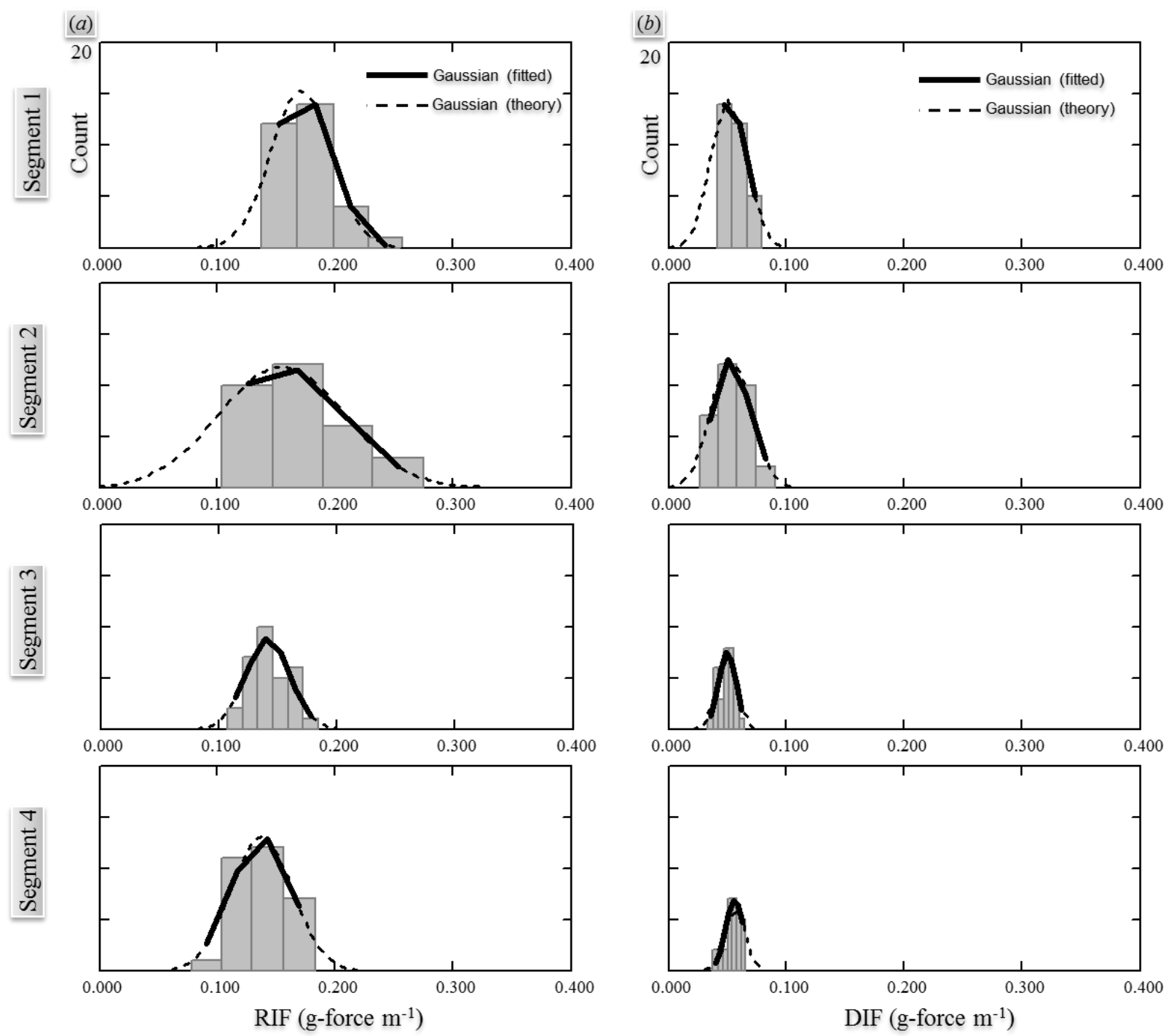

Figure 5.1 For each segment, the a) RIF and the b) DIF distributions from the bus traversals

Even with only 31 measurements for each segment, the average $\mathrm{MOE}_{95}$ for all DIF measurements was $6.5 \%$. 
Table 5.5 RIF statistics and parameters of the distribution fit

\begin{tabular}{|c|c|c|c|c|}
\hline & \multicolumn{4}{|c|}{ Road Impact Factors } \\
\hline Buses & Segment 1 & Segment 2 & Segment 3 & Segment 4 \\
\hline Traversals & 31 & 31 & 31 & 31 \\
\hline Number of Buses & 9 & 12 & 9 & 9 \\
\hline Data Mean & 0.178 & 0.168 & 0.143 & 0.138 \\
\hline Data Std. Dev. & 0.023 & 0.041 & 0.018 & 0.021 \\
\hline $\mathrm{MOE}_{95}$ & 4.729 & 8.961 & 4.608 & 5.639 \\
\hline \multicolumn{5}{|l|}{ Distribution Fit } \\
\hline$d f$ & 1 & 1 & 3 & 1 \\
\hline$\chi^{2}(\alpha=5 \%)$ & 3.841 & 3.841 & 7.815 & 3.841 \\
\hline$\chi^{2}$ Data & 1.472 & 0.49 & 2.489 & 1.33 \\
\hline$\chi^{2}$ Significance $\%$ & 22.507 & 48.391 & 47.728 & 24.882 \\
\hline Amplitude & 0.992 & 1.578 & 0.41 & 0.853 \\
\hline Mean & 0.171 & 0.154 & 0.141 & 0.137 \\
\hline Std. Dev. & 0.026 & 0.053 & 0.019 & 0.026 \\
\hline
\end{tabular}

Table 5.6 DIF statistics and parameters of the distribution fit

\begin{tabular}{|c|c|c|c|c|}
\hline \multirow[b]{2}{*}{ Buses } & \multicolumn{4}{|c|}{ Driver Impact Factors } \\
\hline & Segment 1 & Segment 2 & Segment 3 & Segment 4 \\
\hline Traversals & 31 & 31 & 31 & 31 \\
\hline Number of Drivers & 9 & 12 & 9 & 9 \\
\hline Data Mean & 0.056 & 0.054 & 0.049 & 0.054 \\
\hline Data Std. Dev. & 0.011 & 0.014 & 0.007 & 0.007 \\
\hline $\mathrm{MOE}_{95}$ & 7.22 & 9.33 & 5.138 & 4.493 \\
\hline \multicolumn{5}{|l|}{ Distribution Fit } \\
\hline$d f$ & 0 & 1 & 4 & 4 \\
\hline$\chi^{2}(\alpha=5 \%)$ & N/A & 3.841 & 9.488 & 9.488 \\
\hline$\chi^{2}$ Data & N/A & 0.297 & 4.487 & 3.369 \\
\hline$\chi^{2}$ Significance $\%$ & N/A & 58.586 & 34.415 & 49.811 \\
\hline Amplitude & N/A & 0.522 & 0.14 & 0.133 \\
\hline Mean & N/A & 0.053 & 0.049 & 0.056 \\
\hline Std. Dev. & N/A & 0.016 & 0.007 & 0.008 \\
\hline
\end{tabular}

This result along with high confidence that the data is normally distributed indicates that the means are consistent estimates of the DIFs. Hence, the relatively narrow DIF spread at these low traversal volumes further indicates that the vehicle operators maintained high consistency in their collective acceleration and deceleration actions throughout the stop-and-go and highly unpredictable conditions of the urban setting. Subsequently, a conclusion that all operators performed in a consistent manner is justifiable because the data set contained no significant outliers. However, this result does not necessarily suggest a reason for the consistent behaviors among drivers. For example, it is not possible to tell whether or not the drivers changed their normal behavior because they were aware of the ride roughness measurements. The researchers did not interview the bus operators in any of these tests. The transit agency made all bus operators aware that researchers were conducting surveys of the route roughness. 


\subsubsection{Sedan Data}

From the theory established via Equation (13), calculating the VIF of the buses requires TRQ measurements from a reference vehicle. Using a single driver limited the number of traversals afforded per segment to significantly fewer than those of the buses. Figure 5.2a plots the histograms and fitted Gaussian distributions of the traversal RIFs measured from the 2005 Pontiac Grand Prix. The segment labeled 2 or 3 are common subsets of the overlapping second and third bus segments. Figure 5.2b shows the corresponding plots for the DIF.
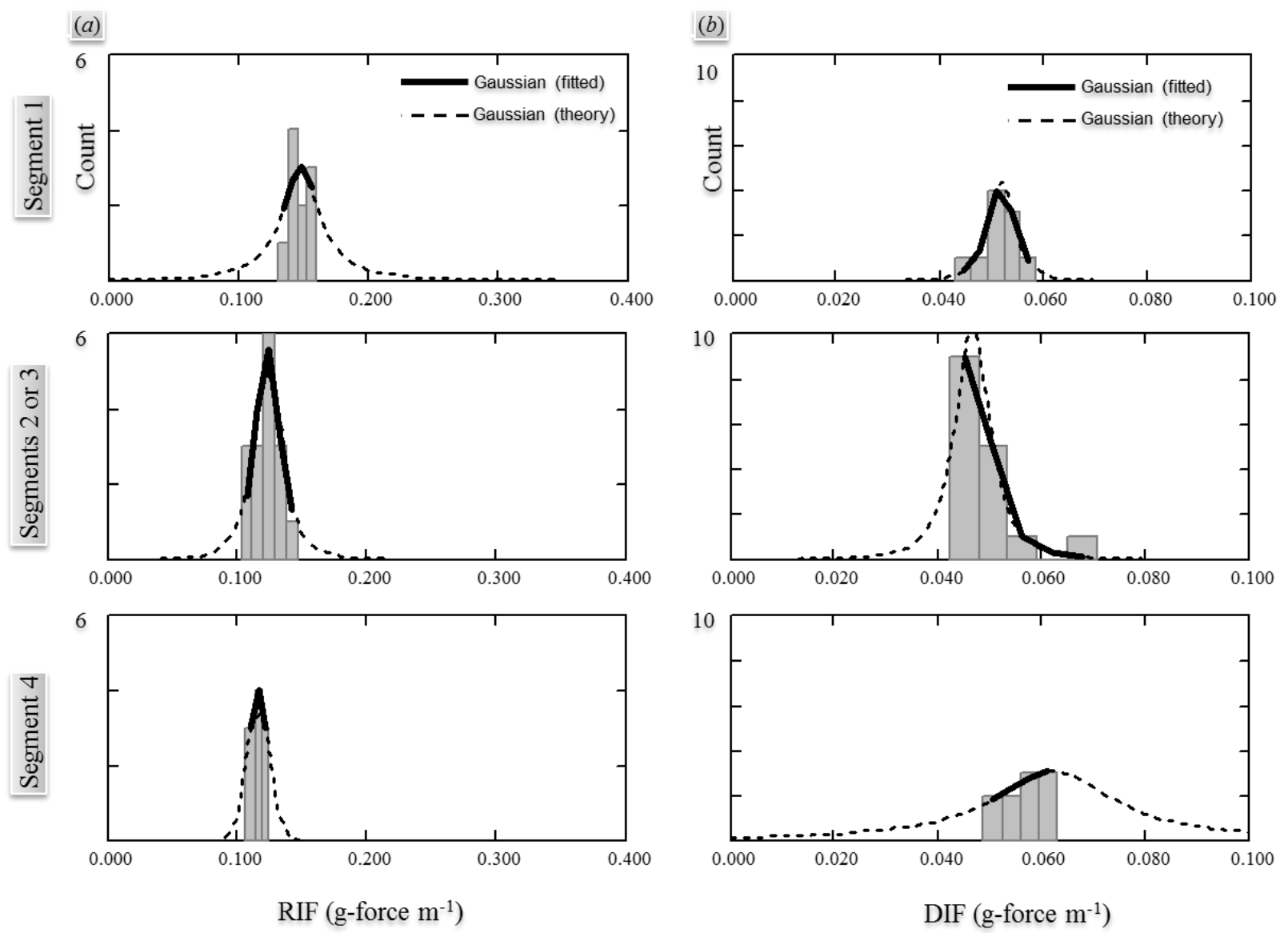

Figure 5.2 For each segment, the a) RIF and the b) DIF distributions of sedan traversals

Table 5.7 and Table 5.8 lists the statistics and parameters of the chi-squared tests for the RIF and DIF distributions, respectively. Similar to the bus traversals, the chi-squared tests indicate that a hypothesis that the tested distributions for segments 1-3 are Gaussian cannot be rejected. For segment 4, there were only three histogram bins, thus limiting the minimum $d f$ needed for chi-squared testing. However, the relatively small $\mathrm{MOE}_{95}$ from only 10 data points provided high confidence that the mean was a consistent estimate of the segment roughness. The average $\mathrm{MOE}_{95}$ for the RIFs and DIFs across all segments was $4.4 \%$ and $6.4 \%$, respectively. Again, the less than 5\% margin-of-error in a 95\% confidence interval for so few data points provide strong evidence that with additional traversals, the mean will converge to the true roughness that riders experience. 
Table 5.7 RIF statistics parameters of the Gaussian fit

\begin{tabular}{lrrr} 
& \multicolumn{3}{c}{ Road Impact Factors } \\
\cline { 2 - 4 } Pontiac Sedan & Segment 1 & Segment 2/3 & Segment 4 \\
\hline Traversals & 10 & 16 & 10 \\
Data Mean & 0.146 & 0.121 & 0.116 \\
Data Std. Dev. & 0.009 & 0.011 & 0.006 \\
MOE $95_{\text {Distribution Fit }}$ & 4.493 & 4.883 & 3.753 \\
& & & \\
$\chi^{2}(\alpha=5 \%)$ & 3.841 & 5.991 & N/A \\
$\chi^{2}$ Data & 1.518 & 1.416 & N/A \\
$\chi^{2}$ Significance \% & 21.789 & 49.272 & N/A \\
Amplitude & 0.16 & 0.166 & N/A \\
Mean & 0.148 & 0.123 & N/A \\
Std. Dev. & 0.017 & 0.011 & N/A \\
\hline
\end{tabular}

Table 5.8 DIF statistics and parameters of the Gaussian fit

\begin{tabular}{|c|c|c|c|}
\hline & \multicolumn{3}{|c|}{ Driver Impact Factors } \\
\hline & Segment 1 & Segment $2 / 3$ & Segment 3 \\
\hline Traversals & 10 & 16 & 10 \\
\hline Data Mean & 0.052 & 0.048 & 0.056 \\
\hline Data Std. Dev. & 0.004 & 0.007 & 0.005 \\
\hline $\mathrm{MOE}_{95}$ & 5.589 & 7.727 & 5.835 \\
\hline \multicolumn{4}{|l|}{ Gaussian Fit } \\
\hline$d f$ & 2 & 2 & 1 \\
\hline$\chi^{2}(\alpha=5 \%)$ & 5.991 & 5.991 & 3.841 \\
\hline$\chi^{2}$ Data & 0.878 & 5.908 & 0.076 \\
\hline$\chi^{2}$ Significance $\%$ & 64.462 & 5.213 & 78.31 \\
\hline Amplitude & 0.033 & 0.106 & 0.137 \\
\hline Mean & 0.052 & 0.047 & 0.062 \\
\hline Std. Dev. & 0.003 & 0.004 & 0.014 \\
\hline
\end{tabular}

Figure 5.3 compares the mean of the RIFs measured from the bus traversals with those measured from the reference sedan traversals of the same segments. Segment 2 represents the common segment 2/3. Two immediate observations are that a) the selected reference sedan suppressed roughness more than the buses, and b) their measurements generally agree in the relative differences of roughness among segments. The DIF for all bus traversals (Table 5.6) and sedan traversals (Table 5.8) were consistent. The consistency in DIFs for buses and the reference sedan indicates that overall, the sedan operator successfully mimicked the velocity patterns of the buses. Subsequently, the RIFs dominated the total ride quality for both the buses and the reference sedan. 


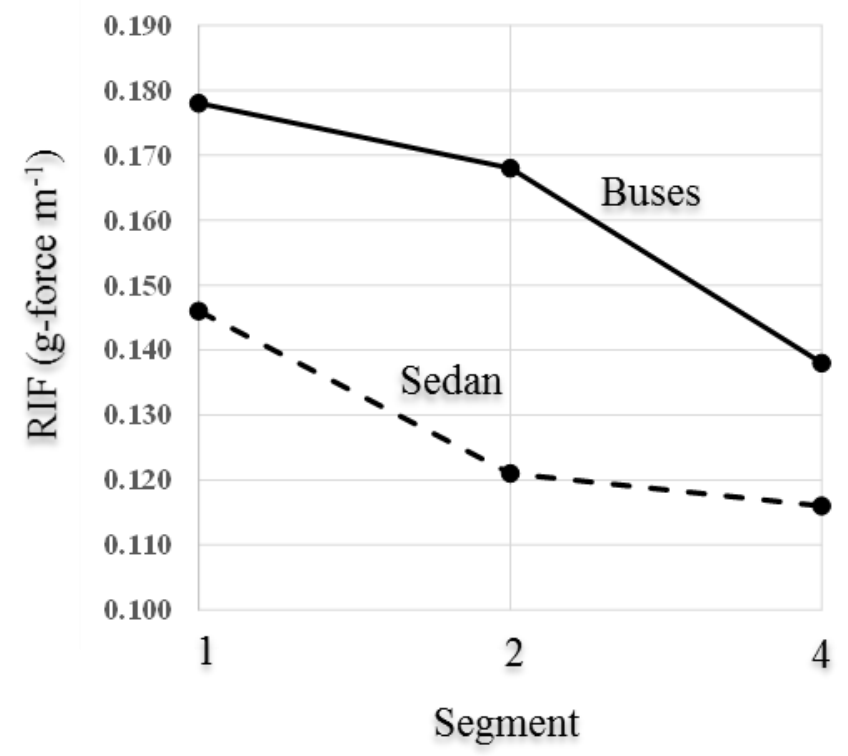

Figure 5.3 Average of the RIFs for the buses and the reference sedan

\subsection{Ride Quality Assessment}

Given the statistical confidence in estimating the RIF and the DIF from their mean values, based on the normality of their distributions established in the previous section, this section formulates the TRQ and the VIF for each segment.

\subsubsection{Total Ride Quality}

For each segment, Table 5.9a, Table 5.9b, and Table 5.9c lists the means of the RIFs and DIFs measured, and the TRQs from all buses, the 2005 reference sedan, and the 2014 reference sedan, respectively.

Table 5.9 Route Ride Quality from (a)

\begin{tabular}{ccccc}
\hline \multicolumn{1}{l}{$(a)$} & \multicolumn{4}{c}{ All Buses } \\
\hline Segment & N & RIF & DIF & TRQ \\
\hline 1 & 31 & 0.178 & 0.056 & 0.187 \\
2 & 31 & 0.168 & 0.054 & 0.176 \\
3 & 31 & 0.143 & 0.049 & 0.151 \\
4 & 31 & 0.138 & 0.054 & 0.148 \\
\hline
\end{tabular}

\begin{tabular}{|c|c|c|c|}
\hline \multicolumn{4}{|c|}{2005 Sedan (Pontiac) } \\
\hline $\mathrm{N}$ & RIF & DIF & TRQ \\
\hline 10 & 0.146 & 0.052 & 0.155 \\
\hline 16 & 0.121 & 0.048 & 0.130 \\
\hline- & - & - & - \\
\hline 10 & 0.116 & 0.056 & 0.129 \\
\hline
\end{tabular}

(c)

\begin{tabular}{cccc}
\multicolumn{4}{c}{ 2014 Sedan (Dodge) } \\
\hline $\mathrm{N}$ & $\mathrm{RIF}$ & DIF & TRQ \\
\hline 3 & 0.138 & 0.049 & 0.146 \\
5 & 0.161 & 0.061 & 0.172 \\
- & - & - & - \\
3 & 0.115 & 0.050 & 0.125 \\
\hline
\end{tabular}

In all cases, the DIFs were much lower than the RIFs. Additionally, as established in the previous section, the average DIF for the buses and the references sedans were consistently similar. Subsequently, the RIFs dominated in all cases. Not surprisingly for a transit urban environment, this study concludes that roadway anomalies that produce roughness were most influential in the overall ride quality experienced. 


\subsubsection{Vehicle Impact Factor}

To examine the statistics of the VIF distribution, Figure 5.4c plots the Gaussian distribution that best fits the histogram of the DIF. Figure 5.4a and Figure 5.4b also examines the distributions of the two VIF components, which are the ratios of the sedan-bus RIFs and DIFs, respectively.

(a)

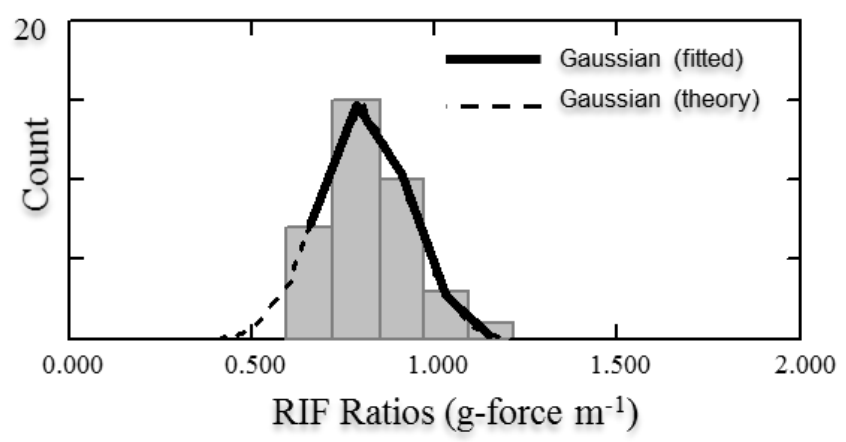

(b)

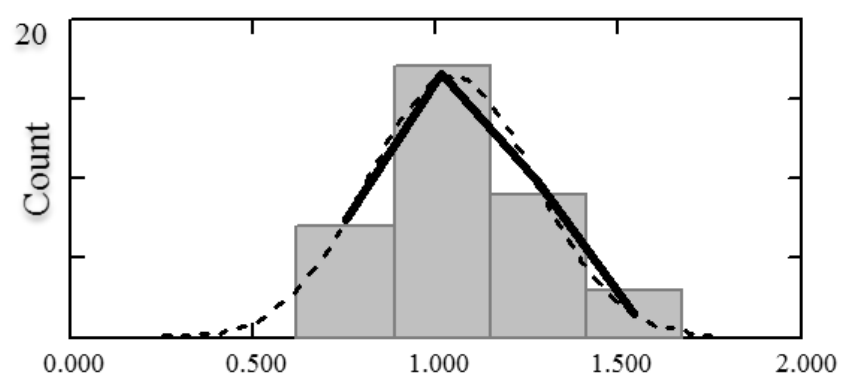

DIF Ratios (g-force $\mathrm{m}^{-1}$ )

(c)

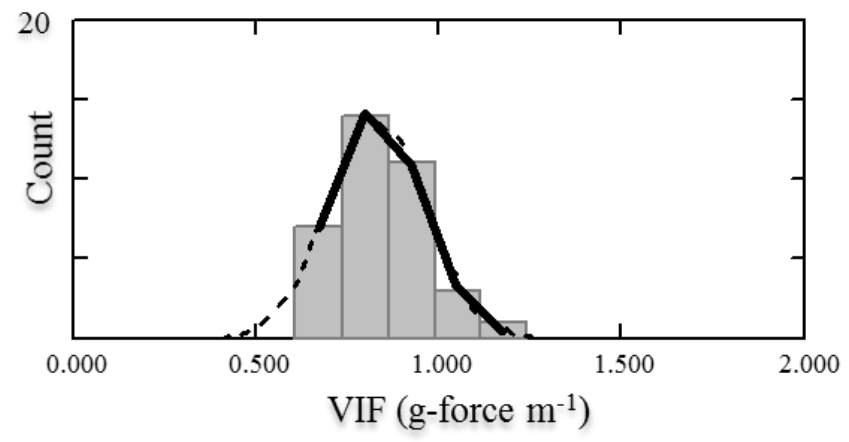

Figure 5.4 For all segments, a) Car/Bus RIF ratios b) Car/Bus DIF ratios and c) VIF distributions

The ratios are formed from a random subset of bus traversals that is the same sample size as all of the available traversals from the reference Pontiac sedan. That is, the VIF sample size is constrained by the available Pontiac sedan traversals, which equals $10+16+10=36$. The random subset of 36 bus traversals is taken from the available pool of $31 \times 4=124$ bus traversals. It is evident that the mean of the RIF ratios was less than unity and that the mean of the DIF ratios was close to unity. This result matches the observation in previous sections that on average, the reference sedan suppressed road roughness more than the buses. However, in a few cases, the buses provided more roughness suppression than the reference sedan as indicated by the right-side tail of the distribution. This result also matches the observation that the bus and reference sedan DIFs were similar. 
Across all segments, the mean RIF for each reference sedan was consistently lower than those for the buses. This indicates that on average, the reference sedans filtered roughness from roadway surface anomalies more than the buses did. This fact is not surprising given the substantial mass differences between buses and sedans, and their different design considerations. Based on Equation (13), Table 5.10 lists, for each segment, the VIF of the buses relative to the two reference vehicles. These results indicate that on average, the reference vehicles provide $15 \%$ more overall roughness suppression.

Table 5.10 Bus VIFs relative to the reference vehicles

\begin{tabular}{crr} 
& \multicolumn{2}{c}{ Bus VIFs } \\
\hline Segment & Pontiac & \multicolumn{1}{c}{ Dodge } \\
\hline 1 & 0.83 & 0.78 \\
2 & 0.74 & 0.98 \\
3 & N/A & N/A \\
4 & 0.87 & 0.85 \\
\hline Average & 0.81 & 0.87
\end{tabular}

Table 5.11 summarizes the statistics and the parameters of the fitted Gaussian distributions. As in the previous chi-squared tests, the significance values of the fits ranged from $19 \%$ to $58.9 \%$, which is much greater than 5\%. Therefore, a hypothesis that the VIFs are normally distributed cannot be rejected. The VIF margin-of-error in a $95 \%$ confidence interval for only 36 samples is $5.2 \%$, which is relatively low.

Table 5.11 Car/Bus statistics and fit of parameters with theoretical Gaussian distributions

\begin{tabular}{lrrr}
\hline Car/Bus Ratios & \multicolumn{1}{l}{ RIF } & \multicolumn{1}{l}{ DIF } & \multicolumn{1}{l}{ VIF } \\
\hline Traversals & 36 & 36 & 36 \\
Data Mean & 0.824 & 1.04 & 0.846 \\
Data Std. Dev. & 0.124 & 0.221 & 0.13 \\
MOE95 & 5.106 & 7.205 & 5.201 \\
Gaussian Fit & & & \\
\multicolumn{1}{l}{$\chi^{2}(\alpha=5 \%)$} & 5.991 & 3.841 & 5.991 \\
$\chi^{2}$ Significance \% & 24.448 & 19.171 & 58.885 \\
Amplitude & 4.446 & 9.441 & 4.664 \\
Mean & 0.804 & 1.041 & 0.828 \\
Std. Dev. & 0.119 & 0.225 & 0.129 \\
\hline
\end{tabular}

Hence, this result presents a high degree of confidence that as the sample size increases for the tested bus fleet, their VIFs will converge to the true value that is estimated by the means indicated in the second row of the table.

It is important to note that for these case studies, measuring the bus VIFs relative to the selected reference sedans in no way suggests that the sedans produce adequate ride quality. VIFs are an objective means to compare the roughness suppression ability of one vehicle relative to another. Future experiments are necessary to establish the maximum acceptable TRQ level from a reference vehicle traversing roads at acceptable levels of smoothness and handling. Only then will the VIFs take on meaning in terms of the adequacy of the ride quality provided. 


\subsection{Ride Quality Perceptions}

Figure 5.5 graphically shows the proportion of bus users rating the ride roughness at each of the qualitative levels shown, for each of the segments. It is clear that as the objective measurements of roughness among the segments decreased, a smaller proportion of the survey respondents rated the ride as being rough. Conversely, a greater proportion of the bus users rated the ride as "very smooth" as the objective measurements of roughness among the segments decreased. In fact, no one traveling on segment 1 , which was measured as the roughest, rated the ride as very smooth. Similarly, a greater proportion of the bus users rated the ride as smooth for the smoother segments than for the rougher segments. Segment 3 was measured at an intermediate roughness level, and it had the largest proportion of ratings at a neutral roughness level. These results are all consistent with expectations.

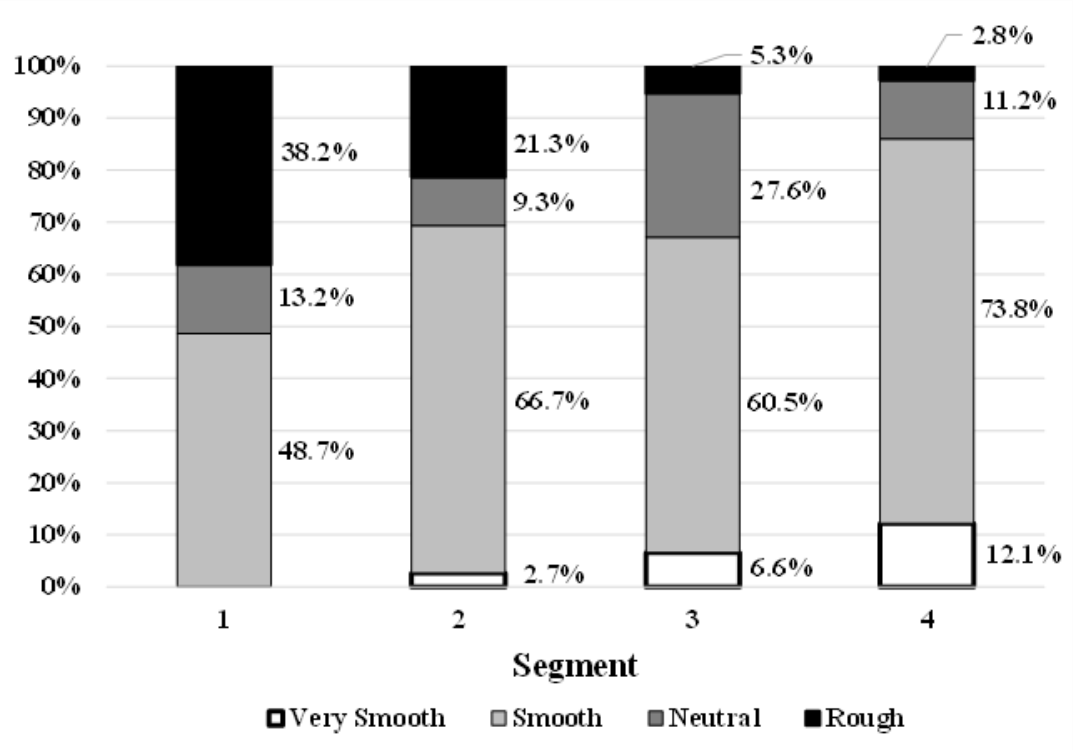

Figure 5.5 For each Segment, Portions of Passengers Providing Ratings at Each Roughness Level

For all trips on each segment, Figure 5.6a plots the average TRQ measured objectively for each of the subjective ratings provided. In this chart, levels 1 through level 4 corresponds to the subjective scale from "very smooth" through "rough," respectively. For example, for the level 2 (smooth) subjective ratings received for all traversals of a segment, the plot indicates the average TRQ measured objectively from those traversals. Figure 5.6b plots the average TRQ measured objectively for each segment. The average TRQ coincided for the two smoothest segments, namely segment 3 and segment 4 . However, the measured TRQ at the first three rating levels consistently increased as the segment roughness increased. In other words, the average subjective rating threshold for a given level of roughness perception increased as the average objective measurements of roughness for a segment increased. In particular, for this case study, the threshold for neutral roughness increased with the actual roughness levels measured. This finding validates the roughness acclimation theory posited in section 2.3.2. That is, the rider's perception of neutrality seemed to have acclimated to the segment roughness that they typically experienced. This result, therefore, leads to an observation that bus riders who use a set of routes regularly, particularly captive riders such as those of this case study, would tend to acclimate to its nominal roughness level. 


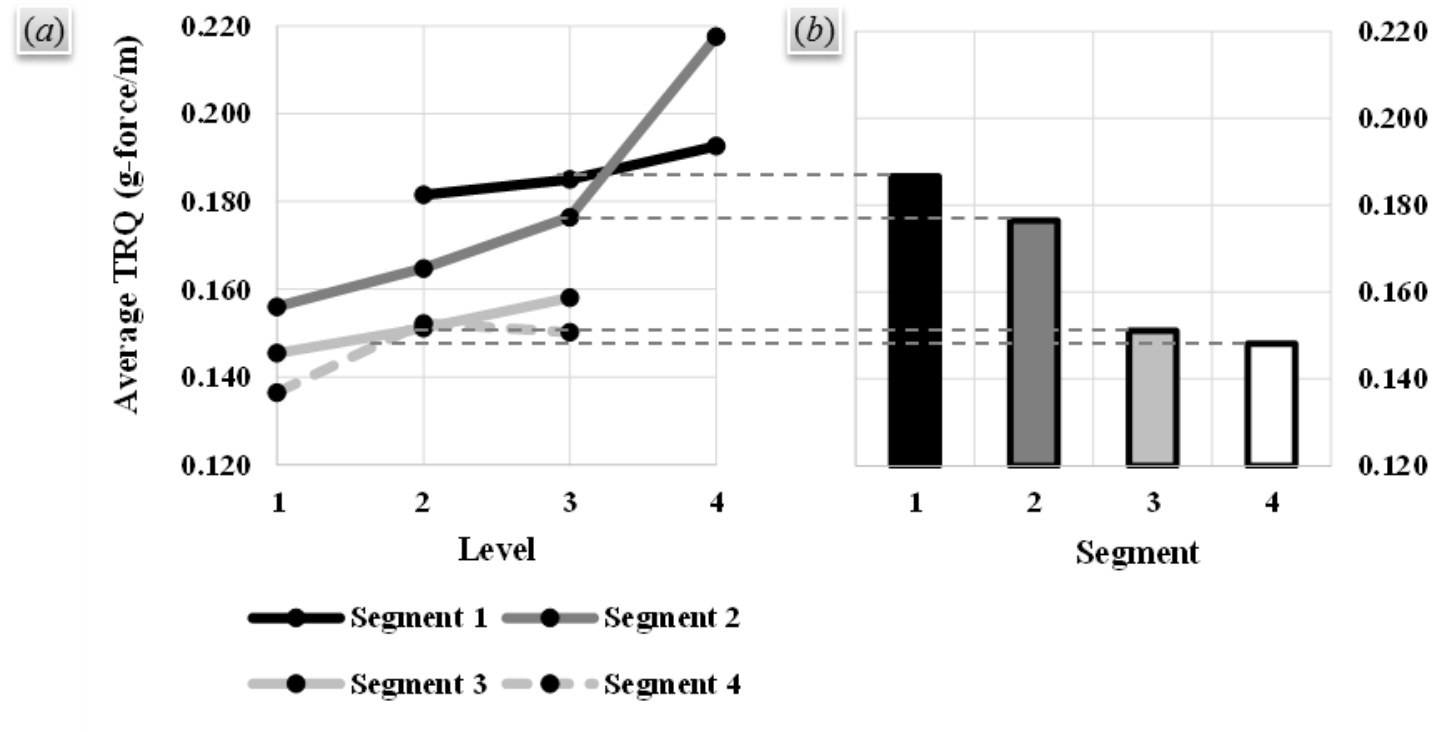

Figure 5.6 For each Route (a) Average TRQ measured at Each Rating b) Average TRQ Measured

The roughness acclimation phenomenon further indicates that subjective evaluations of road condition, vehicle handling, or operator performance could lead to non-uniform ratings and significant biases. This is a significant and important finding that may encourage practitioners to revisit the effectiveness of subjective methods to characterize ride quality. 


\section{CONCLUSIONS}

The notion of transit ride quality could encompass a broader variety of factors beyond road disturbances, operator behaviors, and vehicle dynamic systems. Highway agencies generally focus on vertical accelerations induced from road unevenness because those measurements directly affect roadway maintenance decisions. This study added lateral and longitudinal accelerations to account for roughness induced from asymmetrical road roughness and operator behaviors. Therefore, the scope of the ride quality characterizations for this study was to assess the degree to which roughness experienced in all directions affects the ride experience on bus transit.

In a case study of the small urban environment of Fargo, North Dakota the authors surveyed the bus riders to classify their qualitative perception of the roughness intensity on four bus-route segments. The survey validated the objective measurements of roughness differences among the segments. Hence, this research provides transit agencies with a cost-effective tool and framework to quantify the total ride quality (TRQ) of transit routes. The ride quality theory developed in this research isolated roughness impacts from road unevenness, operator behavior, and vehicle responses. These factors are respectively the RIFs, DIFs, and VIFs defined earlier. A smartphone app collected the inertial and speed data, and the roughness characterization models transformed the data into the three impact factors, and then integrated them to produce the TRQ.

\subsection{Ride Quality Measurements and Perceptions}

This section summarizes those conclusions that relate to the objective measurements of ride quality, the perception of roughness levels experienced, and other characteristics of the ridership.

1) The measurements of all factors that affect TRQ were consistent among all the road segments tested. A hypothesis that the factors were normally distributed could not be rejected. Therefore, the mean values are consistent estimates of the true roughness experienced. The low margins-oferror in a 95\% confidence interval together with the normal distribution of at least 30 samples anticipates that the variance of the mean will continue to diminish with higher levels of vehicle traversals.

2) The RIFs were consistent across all segments tested for both the buses and the reference sedans. The RIFs dominated the TRQ in all cases. This result indicated that roughness from roadway anomalies or roadway unevenness dominated the TRQ.

3) Previous studies have determined that vertical vibrations cause human discomfort. Given the fact that the RIFs dominated the vibration levels experienced, the RIFs alone may be used to quantify the discomfort level of a ride.

4) The DIFs were consistent with relatively narrow spreads across all segments tested. They were comparable among buses and the reference sedans. There were also no outliers in the data set. This result indicated that the operators handled their vehicles in a similar and consistent manner, including their velocity profile patterns. However, this result does not necessarily suggest a reason for the consistent behaviors among drivers. For example, it is not possible to tell whether or not the drivers changed their normal behavior because they were aware of the ride roughness testing.

5) The VIF measurements were consistent across all segments tested. On average, the reference vehicles provided $15 \%$ more roughness suppression than the buses. However, this fact is not surprising because of the substantial mass differences between the buses and the sedans, and their 
different design considerations. Furthermore, these results do not suggest that the reference sedans provided adequate ride quality because the VIFs provide only an objective comparison of the relative vehicle responses to inertial excitations.

6) A majority of the riders were captive. However, a noteworthy proportion (18\%) had access to alternative ride modes. That is, the proportion of passengers with access to ride alternatives ranged from approximately $12 \%$ to $24 \%$, with an average of $18 \%$ across all routes. This suggests that there is an opportunity to encourage more bus users to select bus transit as their primary mode of transportation by addressing factors that would increase the attractiveness of public bus transit. By extension, therefore, programs that encourage mode shift to bus transit would also likely retain non-captive riders.

7) Ride smoothness mattered to a majority (63\%) of the passengers across all routes. Their responses indicated that a smooth ride is either "very important" or "somewhat important." Ride smoothness did not matter for only about $9 \%$ of the passengers. The response was neutral for the remainder $(28 \%)$ of the passengers.

8) The proportion of respondents for which ride smoothness mattered increased from $50 \%$ to $69.2 \%$ as the objectively measured segment roughness decreased. This phenomenon suggests that as passengers adapted or acclimated to the smoother rides, their perception of ride roughness will become more negative.

9) Comfort was the top reason (75\%) that smoothness mattered. Other reasons provided were the ability to read or text $(22 \%)$, and health reasons $(3 \%)$.

10) A majority of the passengers (79\%) who perceived the ride to be "rough" would not consider other modes of transportation because of the roughness. However, a significant proportion (21\%) would consider other modes when the ride is too rough. Of that group, there were no responses that a smooth ride was "Not Important," thus validating that roughness would be their primary reason for considering other modes.

11) The proportion of riders who would consider other modes diminished rapidly as the measured segment roughness decreased.

12) The previous two findings provide strong evidence that excessive roughness is a factor in mode choice for a significant portion of the riders, at least in this case study.

\subsection{Roughness Acclimation Theory}

In addition to the above conclusions, this study presented and validated a roughness acclimation theory. Passengers assigned a mid-range roughness rating to the average roughness measured objectively for any segment. Therefore, the value of the mid-range ratings increased with segment roughness and visa-versa. However, within a segment, perceptions of roughness levels that were below and above the mid-range values corresponded to the objective measurements of lower and higher values, respectively. In essence, passengers as a group tended to translate the mid-range of the perceived roughness scale to values that matched the average roughness measured for a given segment.

These findings indicate that humans adapt to roughness levels because the thresholds for their subjective perception of a given roughness intensity increases with the roughness that they typically experience. This phenomenon is likened to temperature acclimation. For example, the temperature that residents of cold climates would perceive as "hot" is typically lower than the corresponding value for residents of warmer 
regions. The implication of the roughness acclimation theory, therefore, is that subjective measures of ride quality could result in non-uniform ratings and significant biases. However, the authors recommend additional case studies in other settings and demographics to evaluate further the roughness acclimation theory. For instance, a study that surveyed the same riders across routes of different roughness levels should remove some of the acclimation effects. The ride duration may also affect the rate of roughness acclimation.

\subsection{Recommendations}

The results of this research provides a low-cost framework for agencies to use for ride quality assessments of their services. Ride quality assessments can inform decisions about operator training, equipment maintenance, and ridership enhancement programs. However, to use the framework in a practical setting, agencies should consider investing in technology transfer that would standardize the data collection app, and also standardize the data transform methods developed. Practical solutions that utilize the framework will require development of data warehousing scheme, data visualization tools, and decision-support platforms that are tailored to the specific applications and business processes. For example, when only the DIF is needed to help optimize operator training programs, the design of the decision-support platform could be simplified for broader appeal to all personnel. Similarly, the design should support a standardized application programmer's interface (API) to provide easy and secure access to the ride quality data so that other agencies could benefit. The system should be capable of accessing ride quality data by the dates and times collected to isolate or eliminate data that corresponds to the timing of specific events, for example, rain or snow.

\subsection{Limitations and Future Research}

It is possible that the captive ridership of this single case study may have produced some biases relating to the stated importance of a smooth ride. Another limitation of this study is that the authors make no attempt to examine the degree of any possible correlation between other convenience factors and the perception of ride smoothness. It is possible that the results would vary with the proportion of frequent riders. It is also possible that the vehicle operators may have behaved differently if they were aware of the ride quality testing underway. The nominal sensor position on a seat near the center position could have resulted in the underestimation of roughness closer to the front or rear axles. Also, the sensor may have missed roughness from lateral vibrations above the seat level that produced head tossing. Also, riders may have perceived differently the roughness produced from the same road unevenness based on the degree of road noise isolation from the variations in VIFs. Hence, the results of this study represent a nominal perception of roughness that was linked to the fleet deployed in this small urban setting.

As mentioned previously, additional research and experiments are recommended in different settings, with multiple lateral and horizontal sensor positions, and across routes with greater roughness variations. Extending the sample size to achieve a lower margin-of-error will further characterize the rate at which the precision of measurements would improve with data volume. Connected vehicle environments promise enormous data volume. Hence, provisioning for the appropriate data transfers from inertial and speed sensors aboard vehicles will become a critical enabler for this application. The authors also recommend future research that will establish the ride quality adequacy of reference vehicles. Such a study could establish a standard TRQ value that is used to determine the VIF for any vehicle, without requiring TRQ measurements from some arbitrary reference vehicle. 


\section{REFERENCES}

AASHTO. 2010. Standard Equipment Specification for Inertial Profiler. Standard M328-10, Washington, DC: American Association of State and Highway Transportation Officials (AASHTO).

Abaynayaka, S. W., H. Hide, G. Morosiuk, and R. Robinson. 1976. Tables for estimating vehicle operating costs on rural roads in developing countries. Victoria: Transport and Road Research Laboratory (TRRL).

Agresti, Alan, and Barbara Finlay. 2009. Statistical Methods for the Social Sciences. 4th. Upper Saddle River: Pearson Prentice Hall.

ASTM. 2015. Standard practice for computing International Roughness Index of roads from longitudinal profile measurements. ASTM Standard E1926-08, West Conshohocken, Pennsylvania: American Society for Testing Materials (ASTM).

—. 1997. Standard Terminology Relating to Vehicle-Pavement Systems. Standard E867. West Conshohocken, PA: American Society of Testing and Materials (ASTM).

Benjamin, Julian M., and Gregory N. Price. 2006. "A Study of the Impact of APTS on Service Quality Perceptions of Elderly and Disabled Riders." Journal of Public Transportation 9 (4).

Brickman, Arthur Donald, W. H. Park, J. C. Wambold, and J. R. Zimmerman. 1972. Road roughness effects on vehicle performance. Report No. TTSC 7207, University Park: Pennsylvania State University.

Bridgelall, R., Y. Huang, Z. Zhang, and F. Deng. 2016. "Precision enhancement of pavement roughness localization with connected vehicles." Measurement Science and Technology (IOP Publishing) 27 (2): 025012.

Bridgelall, Raj. 2014. "Connected Vehicle Approach for Pavement Roughness Evaluation." Journal of Infrastructure Systems (American Society of Civil Engineers) 20 (1): 04013001 (1-6). doi:10.1061/(ASCE)IS.1943-555X.0000167.

Bridgelall, Raj. 2014. "Inertial Sensor Sample Rate Selection for Ride Quality Measures." Journal of Infrastructure Systems (American Society of Civil Engineering) 21 (2): 04014039 (1-5). doi:10.1061/(ASCE)IS.1943-555X.0000225.

Bridgelall, Raj. 2015. "Precision bounds of pavement deterioration forecasts from connected vehicles." Journal of Infrastructure Systems (American Society of Civil Engineers) 21 (1): 04014033 (1-7).

Brown, Doug, Wei Liu, and Theunis F. P. Henning. 2010. Identifying Pavement Deterioration by Enhancing the Definition of Road Roughness. Research Report 430, Wellington, New Zealand: NZ Transport Agency, 66.

Cantisani, Giuseppe, and Giuseppe Loprencipe. 2010. "Road Roughness and Whole Body Vibration: Evaluation Tools and Comfort Limits." Journal of Transportation Engineering (American Society of Civil Engineers) 136 (9): 818-826.

Carey, William N. Jr., and Paul E. Irick. 1960. The Pavement Serviceability - Performance Concept. Bulletin 250, National Research Council, Washington, D.C.: Highway Research Board, 40-58.

Dawkins, Jeremy, David Bevly, Buzz Powell, and Richard Bishop. 2011. Investigation of Pavement Maintenance Applications of Intellidrive. Virginia: University of Virginia: DOT Pooled Fund Study.

Deusen, B.D. Van. 1967. Analytical techniques for designing riding quality. Technical Paper 670021, Warrendale, PA: Society of Automotive Engineers.

Dittmar, Hank, and Gloria Ohland, . 2012. The new transit town: best practices in transit-oriented development. Island Press.

Douangphachanh, Viengnam, and Hiroyuki Oneyama. 2013. "A Study on the Use of Smartphones for Road Roughness Condition Estimation." Journal of the Eastern Asia Society for Transportation Studies (Eastern Asia Society for Transportation Studies) 10: 1551-1564. doi:10.11175/easts.10.1551. 
Dreyer, C M W, and Wynand J vd M Steyn. 2015. "Evaluation of the effect of deteriorating riding quality on bus-pavement interaction." Journal of the South African Institution of Civil Engineering (The South African Institution Of Civil Engineering) 57 (3): 2-8.

Du, Yuchuan, Chenglong Liu, Difei Wu, and Shengchuan Jiang. 2014. "Measurement of International Roughness Index by Using Z-Axis Accelerometers and GPS." Mathematical Problems in Engineering (Hindawi Publishing Corporation) 10. doi:http://dx.doi.org/10.1155/2014/928980.

Dunlop, Ian N., Jeffrey M. Casello, and Sean T. Doherty. 2015. "Tracking the Transit Rider Experience: Using Smartphones to Measure Comfort and Well-Being Throughout the Trip." Transportation Research Board 94th Annual Meeting. Washington, D.C.: National Academies of Sciences.

Dyer, Stephen A., Ryan Boyd, and Justin S. Dyer. 2005. Refinement of Measurement Techniques of Road Profile and International Roughness Index (IRI) to Support the KDOT Pavement Management System (PMS) Annual Road-Condition Survey Research. Research Report K-TRAN: KSU-99-7, Manhattan, Kansas: Kansas State University (Department of Civil Engineering) for the Kansas Department of Transportation (KDOT), 149.

Gillespie, T. D., M. W. Sayers, and C. A. V. Queiroz. 1986. The International Road Roughness Experiment: Establishing Correlation and Calibration Standard for Measurement. Technical Report No. 45, Washington, D.C.: The World Bank, 464.

Gillespie, Thomas D. 1992. "Everything You Always Wanted to Know about the IRI, But Were Afraid to Ask!" Road Profile Users Group Meeting. Lincoln, Nebraska: The University of Michigan Transportation Research Institute.

Gillespie, Thomas D. 1981. Technical Considerations in the Worldwide Standardization of Road Roughness Measurement. Washington, D.C.: World Bank Technical Report UM-HSRI-81-28.

Griffin, M. J. 1990. Handbook of Human Vibration. New York: Elsevier.

Hudson, W. Ronald, Dan Halbach, John P. Zaniewski, and Len Moser. 1983. "Root-Mean-Square Vertical Acceleration as a Summary Roughness Statistic." Edited by Thomas D. Gillespie and Michael Sayers. Measuring Road Roughness and Its Effects on User Cost and Comfort: A Symposium Sponsored by ASTM Committee E-17 on Traveled Surface Characteristics. Bal Harbour, Florida: American Society for Testing and Materials (ASTM). 3-24.

Hveem, F. N. 1960. "Devices for Recording and Evaluating Pavement Roughness." Highway Research Board Bulletin 264 1-26. http://www.dot.ca.gov/newtech/researchreports/1959-1960/60-09.pdf.

Hyman, William Albert, A. D. Horn, O. Jennings, F. Hejl, and T. Alexander. 1990. Improvements in data acquisition technology for maintenance management systems. NCHRP Report 334, Washington, D.C.: Transportation Research Board.

ISO 2631-1. 1997. Mechanical shock and vibration: Evaluation of human exposure to whole-body vibration. ISO Standard, Geneva: International Organization for Standardization (ISO).

Janoff, Michael S. 1990. "The Prediction of Pavement Ride Quality from Profile Measurements of Pavement Roughness." In Surface Characteristics of Roadways: International Research and Technologies, edited by W. E. Meyer and J. Reichert, 259-276. Philadelphia: American Society of Testing and Materials (ASTM).

Jazar, Reza N. 2008. Vehicle Dynamics: Theory and Applications. New York: Springer.

Karamihas, Steven M. 2016. Measuring, Characterizing, and Reporting Pavement Roughness of LowSpeed and Urban Roads. Research in Progress, Washington, D.C.: Transportation Research Board of the National Academies. Accessed October 12, 2015. http://apps.trb.org/cmsfeed/TRBNetProjectDisplay.asp?ProjectID=3404.

Katicha, Samer W., John El Khoury, and Gerardo W. Flintsch. 2015. "Assessing the Effectiveness of Probe Vehicle Acceleration Measurements in Estimating Road Roughness." International Journal of Pavement Engineering (Taylor \& Francis) Online. doi:10.1080/10298436.2015.1014815.

Klaubert, Earl C. 2001. Highway effects on vehicle performance. FHWA-RD-00-164, Washington, D.C.: Federal Highway Administration (FHWA). 
Kropáč, Oldřich, and Peter Múčka. 2005. "Be careful when using the International Roughness Index as an indicator of road unevenness." Journal of Sound and Vibration (Elsevier Ltd.) 287 (4-5): 9891003. doi:10.1016/j.jsv.2005.02.015.

Ksaibati, Khaled, Ronald McNamara, William Miley, and Jamshid Armaghani. 1999. "Pavement Roughness Data Collection and Utilization." Transportation Research Record: Journal of the Transportation Research Board (Transportation Research Board of the National Academies) 1655: 86-92. doi:10.3141/1655-12.

Mayton, A. G., N. K. Kittusamy, D. H. Ambrose, C. C. Jobes, and M. L. Legault. 2008. "Jarring/jolting exposure and musculoskeletal symptoms among farm equipment operators." International Journal of Industrial Ergonomics (Elsevier) 38 (9): 758-766.

McGhee, Kenneth H. 2004. Automated pavement distress collection techniques. NCHRP Synthesis 334, Washington, D.C.: National Cooperative Highway Research Program (NCHRP).

Múčka, Peter. 2015. "Current Approaches to Quantify the Longitudinal Road Roughness." International Journal of Pavement Engineering (Taylor \& Francis) Online. doi:10.1080/10298436.2015.1011782.

Nakamura, Velma F., and Harold L. Michael. 1963. "Serviceability Ratings of Highway Pavements." 42nd Annual Meeting of the Highway Research Board. Washington, D.C.: Highway Research Record. 1-36.

Papagiannakis, A. Tom. 1997. "The Need for a New Pavement Roughness Index; RIDE." International Truck \& Bus Meeting \& Exposition. Washington, D.C.: Society of Automotive Engineers International. doi:10.4271/973267.

Park, W. H. 1976. "Correlation of Objective and Subjective Bus-Ride Ratings." Transportation Research Record (Transportation Research Board) (584): 55-63.

Perera, R. W., C. Byrum, and S.D. Kohn. 1998. Investigation of Development of Pavement Roughness. FHWA-RD-97-147, Washington, D.C.: Federal Highway Administration (FHWA). http://www.fhwa.dot.gov/publications/research/infrastructure/pavements/ltpp/97147/97147.pdf.

Peterson, Del, and Michael Molloy. 2007. "Advanced Small Transit Vehicle Technology Study." Publication No. 195, Upper Great Plains Transportation Institute, North Dakota State University, Fargo, ND.

Rizenbergs, Rolands L. 1965. Accelerometer Method of Riding-Quality Testing. Research Report KYHPR-64-25; HPS-HPR-1(26), Lexington, Kentucky: Kentucky Department of Highways, 47.

Sharmin, Tania, and Koen Steemers. 2015. "Use of microclimate models for evaluating thermal comfort: Identifying the gaps." International Conference CISBAT 2015 Future Buildings and Districts Sustainability from Nano to Urban Scale. Switzerland: Ecole polytechnique fédérale de Lausanne (EPFL). 895-900.

Spagnolo, Jennifer, and Richard De Dear. 2003. "A field study of thermal comfort in outdoor and semioutdoor environments in subtropical Sydney Australia." Building and Environment (Elsevier) 38 (5): 721-738.

Spangler, Elson B., and William J. Kelley. 1966. "GMR Road Profilometer -- A Method for Measuring Road Profile." 44th Annual Meeting of the Highway Research Board. Washington, DC: Highway Research Board. 27-54. http://trid.trb.org/view.aspx?id=104787.

The Transtec Group. 2012. Smoothness Specifications Online - Overview of Current Practices. The Transtec Group, Inc. March 28. Accessed March 28, 2015. SmoothPavements.com.

Todd, Kevin B., and Bohdan T. Kulakowski. 1989. "Simple Computer Models for Predicting Ride Quality and Pavement Loading for Heavy Trucks." Transportation Research Record (Transportation Research Board) (1215): 137-150.

USDOT. 2015. Beyond Traffic 2045: Trends and Choices. Washington, D.C.: United States Department of Transportation.

Yagi, Koichi. 2013. "A Measuring Method of Road Surface Longitudinal Profile from Sprung Acceleration and Verification with Road Profiler." Journal of Japan Society of Civil Engineers, Ser. E1 (Pavement Engineering) (Japan Science and Technology (JST)) 69 (3): 1-7. 
Zhang, Zong Tao, Quan Man Zhao, and Wan Qiao Yang. 2014. "Pavement Roughness Indices Related to Riding Comfort." In Applied Mechanics and Materials (Trans Tech Publications) 505-506: 180183. doi:10.4028/www.scientific.net/AMM.505-506.180. 